\title{
Anesthesia and Surgery Impair Blood-Brain Barrier and Cognitive Function in Mice
}

\author{
Siming Yang ${ }^{1,2 t}$, Changping Gu $^{2,37}$, Emiri T. Mandeville ${ }^{4}$, Yuanlin Dong ${ }^{2}$, Elga Esposito ${ }^{4}$, \\ Yiying Zhang ${ }^{2}$, Guang Yang ${ }^{5}$, Yuan Shen ${ }^{6}$, Xiaobing Fu ${ }^{1}$, Eng H. Lo ${ }^{4}$ and Zhongcong Xie ${ }^{2 *}$

\begin{abstract}
${ }^{1}$ Key Laboratory of Wound Repair and Regeneration of PLA, College of Life Sciences, General Hospital of PLA, Medical College of PLA, Beijing, China, ${ }^{2}$ Geriatric Anesthesia Research Unit, Department of Anesthesia, Critical Care and Pain Medicine, Massachusetts General Hospital, Harvard Medical School, Charlestown, MA, United States, ${ }^{3}$ Department of Anesthesiology, Shandong Provincial Qianfoshan Hospital, Jinan, China, ${ }^{4}$ Neuroprotection Research, Radiology and Neurology, Massachusetts General Hospital, Harvard Medical School, Charlestown, MA, United States, ${ }^{5}$ Department of Anesthesiology, Perioperative Care and Pain Medicine, New York University School of Medicine, New York, NY, United States, ${ }^{6}$ Department of Psychiatry, Tenth People's Hospital of Tongji University, Shanghai, China
\end{abstract}

\section{OPEN ACCESS}

Edited by:

Niccolo Terrando,

Duke University, United States

Reviewed by:

Shane Antony Liddelow, Stanford University, United States

Jae Kyu Ryu,

Gladstone Institutes, United States

*Correspondence:

Zhongcong Xie

zxie@mgh.harvard.edu

tThese authors have contributed equally to this work.

Specialty section:

This article was submitted to Inflammation,

a section of the journal

Frontiers in Immunology

Received: 15 June 2017

Accepted: 14 July 2017

Published: 09 August 2017

Citation:

Yang S, Gu C, Mandeville ET, Dong Y, Esposito E, Zhang Y, Yang G, Shen Y,

Fu X, Lo EH and Xie Z (2017)

Anesthesia and Surgery Impair

Blood-Brain Barrier and Cognitive

Function in Mice.

Front. Immunol. 8:902.

doi: 10.3389/fimmu.2017.00902
Blood-brain barrier (BBB) dysfunction, e.g., increase in BBB permeability, has been reported to contribute to cognitive impairment. However, the effects of anesthesia and surgery on BBB permeability, the underlying mechanisms, and associated cognitive function remain largely to be determined. Here, we assessed the effects of surgery (laparotomy) under 1.4\% isoflurane anesthesia (anesthesia/surgery) for $2 \mathrm{~h}$ on BBB permeability, levels of junction proteins and cognitive function in both 9- and 18-month-old wild-type mice and 9-month-old interleukin (IL)-6 knockout mice. BBB permeability was determined by dextran tracer (immunohistochemistry imaging and spectrophotometric quantification), and protein levels were measured by Western blot and cognitive function was assessed by using both Morris water maze and Barnes maze. We found that the anesthesia/surgery increased mouse BBB permeability to 10-kDa dextran, but not to 70-kDa dextran, in an IL-6-dependent and age-associated manner. In addition, the anesthesia/surgery induced an age-associated increase in blood IL-6 level. Cognitive impairment was detected in 18-month-old, but not 9-month-old, mice after the anesthesia/surgery. Finally, the anesthesia/surgery decreased the levels of $\beta$-catenin and tight junction protein claudin, occludin and ZO-1, but not adherent junction protein VE-cadherin, E-cadherin, and p120-catenin. These data demonstrate that we have established a system to study the effects of perioperative factors, including anesthesia and surgery, on BBB and cognitive function. The results suggest that the anesthesia/ surgery might induce an age-associated BBB dysfunction and cognitive impairment in mice. These findings would promote mechanistic studies of postoperative cognitive impairment, including postoperative delirium.

Keywords: anesthesia/surgery, interleukin-6, blood-brain barrier, age, cognition

\section{INTRODUCTION}

Anesthesia and surgery have been shown to induce postoperative cognitive impairment in rodents [(1-10), reviewed in Ref. (11)]. However, the underlying mechanism by which the anesthesia/surgery causes cognitive impairment remains largely to be determined. 
The blood-brain barrier (BBB) is composed of blood vessels with endothelial cells with extremely low rates of paracellular vesicular transport (12) and transcellular vesicular transport (transcytosis) [(13-15), reviewed in Ref. (16)]. The BBB provides a safe environment for the central nervous system (CNS), which is free of pathogens and toxins in normal conditions [reviewed in Ref. (17)].

Compromised BBB function might contribute to the cognitive impairment, brain damage, and neurodegenerative disorders, e.g., Alzheimer's disease [(18, 19), reviewed in Ref. $(16,20,21)]$. Specifically, peripheral inflammation can profoundly affect the function of the CNS, including cognitive impairment and delirium, through a compromised BBB (22-24). Stranahan et al. reported that $\mathrm{BBB}$ dysfunction (e.g., increase in $\mathrm{BBB}$ permeability) might induce cognitive impairment in obese and diabetic patients by allowing macrophage infiltration and trafficking of interleukin (IL)- $1 \beta$ from peripheral monocytes to the brain (25). Zhang et al. suggested that BBB dysfunction caused CNS inflammation and cognitive impairment (26). Based on these findings, we aimed to assess the effects of the anesthesia/surgery on BBB permeability, the potential underlying mechanisms and cognitive function in the current studies.

Our previous studies have shown that surgery under local anesthesia induces an age-dependent cognitive impairment in mice $(6,7)$, and anesthetic isoflurane $(27)$ and sevoflurane $(28,29)$ can increase IL-6 level. Therefore, we also sought to determine whether the anesthesia/surgery-induced change in $\mathrm{BBB}$ permeability and cognitive function was associated with the advanced age and dependent on IL-6. Finally, we compared the effects of anesthesia/surgery on the levels of $\beta$-catenin, tight junction proteins (claudin, occludin, and ZO-1) [(30), reviewed in Ref. (16)], and adherent junction protein (VE-cadherin, E-cadherin, and p120-catenin) [(31), reviewed in Ref. (16)].

The objective of the current studies was to determine the effects of the anesthesia/surgery on BBB permeability, cognitive function and blood IL-6 levels, and brain levels of tight junction and adherent junction proteins in adult and older mice, which could lead to the further mechanistic investigation of postoperative cognitive impairment, including postoperative delirium. Our hypothesis is that the anesthesia/surgery induces an ageassociated and IL-6 dependent increase in BBB permeability, leading to cognitive impairment in mice.

\section{MATERIALS AND METHODS}

\section{Mice Surgery and Treatment}

All experiments were performed in accordance with the National Institutes of Health guidelines and regulations. The animal protocol was approved by the Massachusetts General Hospital (Boston, MA, USA) Standing Committee on the Use of Animals in Research and Teaching. Efforts were made to minimize the number of animals used. Wild-type C57BL/6J female mice (9-month-old, The Jackson Laboratory, Bar Harbor, ME, USA; and 18-month-old, National Institute of Aging, Bethesda, MD, USA), and 9-month-old IL-6 gene knockout female mice (B6.129S2-Il6tm1Kopf/J, The Jackson Laboratory) were used in the studies.
We only used female mice in the current studies because our previous studies showed that the female mice were more vulnerable to the development of cognitive impairment following the same anesthesia/surgery (32). Mice were randomly assigned to the anesthesia/surgery group or control group by weight. The 18-month-old mice are only available through National Institute of Aging, thus cannot be purchased from same company that provides the 9-month-old mice. Mice in the anesthesia/surgery group had a simple laparotomy under isoflurane anesthesia using the methods described in our previous studies $(10,33)$. Specifically, we anesthetized each of the mice using $1.4 \%$ isoflurane in $100 \%$ oxygen in a transparent acrylic chamber. Fifteen minutes after the induction, we moved the mouse out of the chamber. Isoflurane anesthesia was maintained via a cone device and one 16-G needle was inserted into the cone near the nose of the mouse to monitor the concentration of isoflurane. We made a longitudinal midline incision from the xiphoid to the $0.5 \mathrm{~cm}$ proximal pubic symphysis on the skin, abdominal muscles, and peritoneum. We then sutured the incision layer by layer with 5-0 Vicryl thread. We applied EMLA cream (2.5\% lidocaine and $2.5 \%$ prilocaine) to the incision site at the end of the procedure, and then every $8 \mathrm{~h}$ until the euthanasia of the mice, to treat the pain associated with the incision. The procedure for each mouse usually lasted about $10 \mathrm{~min}$ and we put the mouse back into the anesthesia chamber for up to $2 \mathrm{~h}$ to receive the rest of the anesthesia consisting of $1.4 \%$ isoflurane in $100 \%$ oxygen. We used this method because surgery could potentiate the anesthesia neurotoxicity and such combination of anesthesia and surgery had been shown to induce cognitive impairment $(10,33)$. We maintained the rectal temperature of the mice at $37 \pm 0.5^{\circ} \mathrm{C}$ during the anesthesia/surgery by using DC Temperature Control System (FHC, Bowdoinham, ME, USA). We returned the mice back to their home cage with food and water available ad libitum after recovering from the anesthesia. The mice in the control group were placed in their home cages with regular room air for $2 \mathrm{~h}$, which was consistent with the condition of non-surgery patients. Our previous studies found that neither the surgery $(6,7)$ nor anesthesia with $1.4 \%$ isoflurane (34) significantly disturbed the blood pressure and blood gas values of the mice. EMLA could treat the pain associated with the surgery in the mice $(6,7)$. The treatment of IL- 6 antibody was performed as described in previous studies with modification (4). Specifically, each of the 18-month-old mice received the $10 \mu \mathrm{g}$ IL- 6 antibody (eBioscence Inc., San Diego, CA, USA, Cat. Number: 16-7061) at $18 \mathrm{~h}$ before the anesthesia/surgery via tail vein injection under brief anesthesia ( $1.4 \%$ isoflurane for $5 \mathrm{~min}$ ). The control mice received saline. We used a single injection of IL- 6 antibody because a single injection of TNF- $\alpha$ antibody had been shown to mitigate the surgery-induced cognitive impairment in mice in the studies by Terrando et al. (35).

\section{Brain Tissue Harvest}

We harvested the brain tissues of the mice for the dextran imaging studies and spectrophotometer quantification of dextran. We harvested both cortex and hippocampus for the Western blot analysis. Each of the mice was perfused with phosphate-buffered saline (PBS) for the spectrophotometric quantification of dextran. 
Specifically, mouse received thoracotomy under brief anesthesia (1.4\% isoflurane for $5 \mathrm{~min}$ ), we inserted a needle to left ventricular of the heart and perfused slowly with sufficient amount of PBS (five times with $30 \mathrm{ml}$ PBS each time) until the PBS exiting from right heart became colorless. We then decapitated the head of each of the mice and harvested the brain tissues. We stored the brain tissues in $\mathrm{a}-80^{\circ} \mathrm{C}$ freezer for future analysis.

\section{Dextran Imaging Studies to Detect BBB Permeability}

Dextran was used to measure BBB permeability as described in previous studies with modifications (15). Specifically, $6 \mathrm{~h}$ after the anesthesia/surgery, each of the mice was briefly anesthetized with $1.4 \%$ isoflurane for $5 \mathrm{~min}$ for the injection of dextran. $100 \mu \mathrm{l}$ $10-\mathrm{kDa}$ dextran tetramethylrhodamine lysine fixable $(4 \mathrm{mg} / \mathrm{ml}$, Catalog number: D3312, Invitrogen) was injected into the mouse through the tail vein. Ten minutes after the injection, each of the mice was decapitated; brain tissues (e.g., cortex) were harvested and fixed by $4 \%$ paraformaldehyde overnight at $4^{\circ} \mathrm{C}$. The brain tissues (e.g., cortex) were cryopreserved in 30\% sucrose and frozen in TissueTek OCT (Sakura). The immunohistochemistry to detect $\mathrm{BBB}$ permeability was performed as described in the previous studies (15) with modifications. Frozen sections (the thickness of each section: $12 \mu \mathrm{m}$ ) from mouse brain hemispheres were cut and used for the immunohistochemistry staining. These sections were postfixed in $4 \% \mathrm{PFA}$ at room temperature $\left(20-25^{\circ} \mathrm{C}\right)$ for $15 \mathrm{~min}$, washed in PBS, and were blocked with $2 \%$ albumin from bovine serum, permeabilized with $0.5 \%$ Triton X-100, and incubated with isolectin B4 (1:200; Catalog number: I21411, Molecular Probes, San Francisco, CA, USA) for the immunohistochemistry imaging of blood vessels. Dextran itself has fluorescence for the detection of immunohistochemistry imaging. Finally, the sections were analyzed in mounting medium (Catalog number: ab104139; Abcam, Cambridge, MA, USA) under a $40 \times$ objective lens of the fluorescence microscope and photos of the sections were taken. These images were analyzed manually with ImageJ (National Institutes of Health, Bethesda, MD, USA). Coronal cortical sections $(12 \mu \mathrm{m})$ of the same rostrocaudal position were used for the analysis. The same threshold was used and the same acquisition parameters were applied to all images. An investigator who was blind to the experimental design manually measured the level (combined with area and intensity) of the dextran tracer-positive area found outside the vessel using ImageJ. For each mouse, we obtained five slices from front, middle, and posterior section of the brain tissue (e.g., cortex). Two images per slice were taken. Therefore, 30 images ( 3 section $\times 5$ slices $\times 2$ images $)$ of each mouse were counted. There were three mice in control group and three mice in the anesthesia/surgery group. Thus, the quantification of the images was based on these 90 images per group.

\section{Spectrophotometric Quantification of Dextran to Detect BBB Permeability}

Spectrophotometric quantification of $10-\mathrm{kDa}$ fluoro-rubydextran tracer (555/580) (4 mg/ml, Catalog number: D1817, Invitrogen) from cortex extracts was used as described in previous studies $(15,36)$. The $100 \mu \mathrm{l}$ dextran tracer was injected into each of the mice via the tail vein under brief anesthesia $(1.4 \%$ isoflurane for $5 \mathrm{~min}$ ) at $1 \mathrm{~h}$ after the anesthesia/surgery. $16 \mathrm{~h}$ after the injection of the tracer, each of the mice was cardiac perfused as described in the Section "Brain Tissues Harvest." Brain tissues (e.g., cortex) were then harvested and the $10-\mathrm{kDa}$ fluoro-rubydextran tracer $(555 / 580)$ from cortex extracts was determined by Spectrophotometric measurement.

\section{Enzyme-Linked Immunosorbent Assay (ELISA) Determination of IL-6}

The mouse IL-6 Immunoassay kit (Catalog number: M6000B, R\&D Systems) was used to determine the levels of IL-6 in mouse blood as described by the protocol associated with the immunoassay kit. Briefly, a monoclonal antibody specific for mouse IL-6 was coated onto the microplates. Wells were incubated for $2 \mathrm{~h}$ at room temperature with test samples (serum) and washed for five times. Then, $100 \mu \mathrm{l}$ of mouse IL- 6 conjugate was added to each well and incubated for another $2 \mathrm{~h}$ and we repeated the washing. Finally, wells were incubated in $100 \mu \mathrm{l}$ of substrate solution for $30 \mathrm{~min}$ and stopped with stop solution $(100 \mu \mathrm{l})$. Determination of the optical density of each well was set at $450 \mathrm{~nm}$ and corrected at $570 \mathrm{~nm}$.

\section{Western Blot Analysis}

Western blot analysis was performed using the methods described in our previous studies (8). Cortex and hippocampus tissues were harvested from 18-month-old mice at 6,12 , and $24 \mathrm{~h}$ after the anesthesia/surgery. Anti- $\beta$-catenin antibody $(92 \mathrm{kDa}$, Cat: \#9562, 1:1,000 dilution, Cell signaling, Danvers, MA, USA), antiphosphorylated $\beta$-catenin antibody (Ser33/37/Thr41, $92 \mathrm{kDa}$, Cat: \#9561, 1:1,000 dilution, Cell signaling), anti-claudin-1 antibody (19 kDa, Cat: ab15098, 1:1,000 dilution, Abcam, Cambridge, MA, USA), anti-occludin antibody (59 kDa, Cat: ab167161, 1:1,000 dilution, Abcam), anti-ZO-1 antibody (250 kDa, Cat: PA5-28858, 1:500 dilution, Thermo Fisher Scientific, Rockford, IL, USA), and anti-VE-cadherin (115 kDa, Cat: ab33168, $1 \mu \mathrm{g} / \mathrm{ml}$, Abcam), anti-E-cadherin antibody (135 kDa, Cat: \#5296, 1:1,000 dilution, Cell signaling) were used to detect the level of the proteins in the cortex and hippocampus of the 18-month-old mice. Samples in different groups were loaded and $\beta$-actin was used to normalize (e.g., determining the ratio of $\beta$-catenin to $\beta$-actin amount) protein levels and control for loading differences in the total protein amount. The quantification of the Western blot was performed as described in previous study (8), we presented changes in protein levels in hippocampus or cortex treated with anesthesia/surgery as a percentage of those in the control group. $100 \%$ of protein level changes refer to control levels for the purpose of comparison to experimental conditions. Signal intensity was analyzed using a Bio-Rad (Hercules, CA, USA) image program.

\section{Morris Water Maze (MWM)}

Morris water maze was carried out to assess spatial learning and memory function as previously described $(7,28)$. The blind procedure was not possible in the MWM studies because of the appearance of the abdominal wound in the mice. Briefly, all mice were trained to swim to a hidden platform in four trials per day for 6 days (days 1-6) starting 3 days after the anesthesia/ 
surgery (Figure 1). Each of the mice was given $90 \mathrm{~s}$ to find the platform and allowed to stay there for $15 \mathrm{~s}$ before being removed from the platform. Mice would be guided to the platform and allowed to stay on the platform for $15 \mathrm{~s}$ if they could not find the platform within $90 \mathrm{~s}$. The platform was placed in the target quadrant in trials within one MWM test, but the starting points were random for each mouse. We measured the time it took for each mouse to reach the platform (escape latency) and used this as the learning score. On the seventh day, we repeated the training same as the previous training (days 1-6). Two hours after the training, we removed the platform and assessed the memory of each mouse by measuring the number of times the mouse crossed the platform area with the same cue (memory score). We compared the learning and memory score and swimming speed between the mice in the control group and the anesthesia/ surgery group.

\section{Barnes Maze}

Barnes maze test was performed by using the methods described in other studies (37-40) with modifications. The blind procedure was not possible in the Barnes maze studies because of the appearance of the abdominal wound in the mice. Barnes maze with a circular open platform (about 90-cm diameter) was located in a quiet area. It had 20 equally spaced holes (one of these holes connects with a small dark recessed chamber called escape box) and was surrounded by a dark curtain with four simple colored-paper shapes (square, circle, triangle, and star) as markers (Stoelting, Wood Dale, IL, USA). A video camera that could capture the entire platform was right above the platform and connected to the Any-Maze animal tracking system software (Stoelting Co., Wood Dale, IL, USA) as described in previous studies $(38,41,42)$. The movement parameters, including escape latency (the total time to find the escape box), escape distance (the total path length of distance traveled), escape speed (mean speed), escape errors (the total error holes searched), and time in target quadrant [the percentage of time spent in the target quadrant, time in target quadrant (\%)], of the mouse before finding the escape box in both training and test were monitored and analyzed via the video camera. The Barnes maze test in the current studies included Barnes maze training test (days 12-15 after the anesthesia/surgery) and Barnes maze test (16 days after the anesthesia/surgery) (Figure 1). On day 11 after the anesthesia/surgery, all of the mice were habituated to the maze. The mouse was placed in the escape box for $2 \mathrm{~min}$ and then placed directly in the hole that led to the escape box for another $4 \mathrm{~min}$. Finally, the mouse was placed under a bucket in the center of the circular platform and motivated to escape under the bright light $(200 \mathrm{~W})$ and noise $(85 \mathrm{~dB})$ stimulation. Mouse was gently guided to the hole connecting to the escape box when it did not go into the escape box 3 min after the light and noise stimulation. Immediately after the mouse entered the tunnel between the hole and the escape box, the buzzer was turned off. Each mouse was allowed to remain in the escape box for $1 \mathrm{~min}$ and then removed and placed back to the home cage.

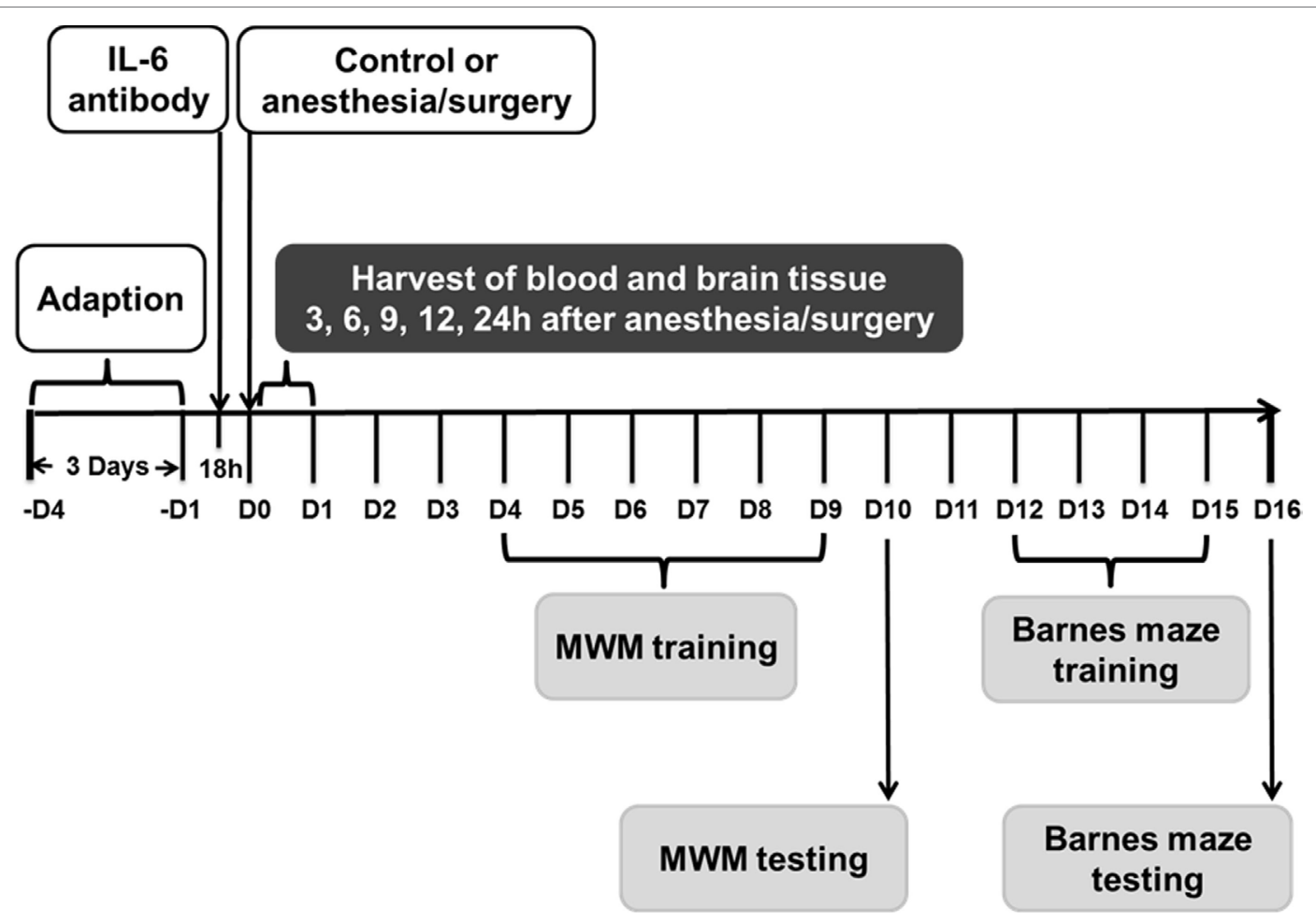

FIGURE 1 | Experimental design. Nine- and eighteen-month-old mice received the anesthesia/surgery or control condition. The blood and brain tissues were harvested at various time points after the anesthesia/surgery. Different group of mice were used for MWM and Barnes maze studies. Interleukin (IL)-6 antibody was used in the intervention studies. MWM, Morris water maze. 
The Barnes maze training test (days 12-15 after the anesthesia/ surgery) consisted of two trials (3 min each trial and $15 \mathrm{~min}$ between the trials) for 4 days. In each trial, the mouse was placed under a bucket in the center of the circular platform for $10 \mathrm{~s}$ and was allowed to escape under the same stimulation of light and aversive noise. Once reaching the escape box, the mouse was allowed to remain in the escape box for $1 \mathrm{~min}$. The mouse was then removed and placed back to the home cage for $15 \mathrm{~min}$ of rest period before returning back for another trial. Between each test, the Barnes maze was cleaned with $75 \%$ alcohol solution to avoid olfactory cues. After the training period, the mice had the Barnes maze test on day 16 after the anesthesia/ surgery (Figure 1). The increases in escape latency, escape distance, escape errors, and decrease in time in target quadrant in the Barnes maze suggests cognitive impairment of the mice (37-40). The decreases in escape speed suggest impairment of locomotor activity. We used the percentage of time in the target quadrant rather than the target preference in the current studies according to the previous studies $(41,43)$.

\section{Statistics}

Data of escape latency, escape distance, escape speed, escape errors, and time in target quadrant were expressed as means \pm SEM. Data of other variables were expressed as means \pm SD. The number of samples was 3 per group for ELISA studies, 4-5 per group for the spectrophotometer quantification of dextran, 90 per group for the immunohistochemistry imaging study, 10 per group for behavior test, and 6 per group for the Western blot studies. In the Barnes maze and Water maze studies, interaction between time and group factors in a two-way ANOVA with repeated measurements was used to analyze the difference of memory curves (e.g., based on escape latency). Post hoc analyses (Bonferroni) were used to compare the difference in all behavior test parameters for each testing day. In the biochemistry studies, one-way ANOVA or two-way ANOVA was used to determine the interaction between group and treatment on the levels of $\beta$-catenin, claudin, occludin, ZO-1, VE-cadherin, E-cadherin, and p120-catenin followed by Bonferroni test for the comparisons. All the protein levels were presented as a percentage of those of the control group. $P$-values less than 0.05 were considered statistically significant. Prism 6 software (Graph Pad Software, Inc., La Jolla, CA, USA) was used to analyze the data.

\section{RESULTS}

\section{Anesthesia/Surgery Increases Extravascular Dextran Level in Mouse Brain in Age-Associated Manner}

The details of the experimental design and performance were summarized in Figure 1. We employed immunohistochemistry staining of blood vessels (green color) and $10-\mathrm{kDa}$ dextran (red color) to determine whether the abdominal surgery under isoflurane anesthesia (anesthesia/surgery) could increase the $\mathrm{BBB}$ permeability in mice. As compared to control condition (Figure 2A, first row), the anesthesia/surgery (Figure 2A, third row) increased the extravascular $10-\mathrm{kDa}$ dextran level in the brain tissues of the 9-month-old mice. The quantification of the immunohistochemistry image showed that the anesthesia/surgery (Figure 2B, gray bar) increased the extravascular $10-\mathrm{kDa}$ dextran level in the brain tissues of mice as compared to the control condition (Figure 2B, white bar) $(P<0.001$, one-way ANOVA and Bonferroni test). These data suggest that the anesthesia/surgery was able to increase BBB permeability of $10-\mathrm{kDa}$ dextran in the 9-month-old mice.

We then assessed the effects of the anesthesia/surgery on extravascular $10-\mathrm{kDa}$ dextran level in the brain tissues of the 18-month-old mice. We found that the anesthesia/surgery induced a greater increase in the extravascular $10-\mathrm{kDa}$ dextran level in the brain tissues of the 18-month-old mice (Figure 2A, fourth row) as compared to the control condition (Figure $\mathbf{2 A}$ second row) or the anesthesia/surgery in the 9-month-old mice (Figure 2A, third row). The quantification of the immunohistochemistry images showed that the anesthesia/surgery in 18-month-old mice (Figure 2B, net bar) increased the extravascular $10-\mathrm{kDa}$ dextran level in the brain tissues of mice as compared to the control condition (Figure 2B, black bar) $(P<0.001$, one-way ANOVA and Bonferroni test) or the anesthesia/surgery condition in the 9-month-old mice (Figure 2B, gray bar) $(P<0.01$, one-way ANOVA and Bonferroni test). These data suggest that the anesthesia/surgery might induce a greater BBB permeability of $10-\mathrm{kDa}$ dextran in the 18 -monthold mice.

Finally, we found that the treatment with IL-6 antibody in the 18-month-old mice (Figure 2A, fifth row, and Figure 2B, dot bar) was able to attenuate the anesthesia/surgery-induced increase in $\mathrm{BBB}$ permeability of $10-\mathrm{kDa}$ dextran (Figure 2A, fourth row, and Figure 2B, net bar). Anesthesia only in the 18-month-old mice did not significantly increase the $\mathrm{BBB}$ permeability of $10-\mathrm{kDa}$ dextran (Figure 2C) as compared to the control condition in the 18-month-old mice (Figure 2A, second row). This image represents one mouse, but the study was repeated in another two mice. Moreover, we employed an IL-6 KO mouse to further assess the effects of IL- 6 on the anesthesia/surgery-induced increase in BBB permeability. We found that there was no significant difference in extravascular $10-\mathrm{kDa}$ dextran level in the brain tissues of the 9-month-old IL-6 knockout mouse between control condition and anesthesia/surgery condition (Figure 2D). The image represents one mouse, but the studies were repeated in another mouse. Taken together, these data suggest that the anesthesia/ surgery-induced increase in $\mathrm{BBB}$ permeability to $10-\mathrm{kDa}$ dextran would be dependent on IL- 6 level.

Notably, the same anesthesia/surgery did not significantly increase $\mathrm{BBB}$ permeability to 70 -kDa dextran in 9- or 18-monthold mice (Figure 2E). The image represents one mouse, but the study was repeated in another two mice. These data suggest that the anesthesia/surgery may only increase BBB permeability to 10-kDa, but not $70-\mathrm{kDa}$, dextran.

Finally, the findings that the anesthesia/surgery did not increase the $\mathrm{BBB}$ permeability to $10-\mathrm{kDa}$ dextran in IL-6 KO mice and in the wild-type mice pre-treated with IL- 6 antibody suggest that the perfusion itself would not increase the BBB permeability to $10-\mathrm{kDa}$ dextran. 
A

9 months
+
Control
$\begin{gathered}18 \text { months } \\ + \\ \text { Control }\end{gathered}$
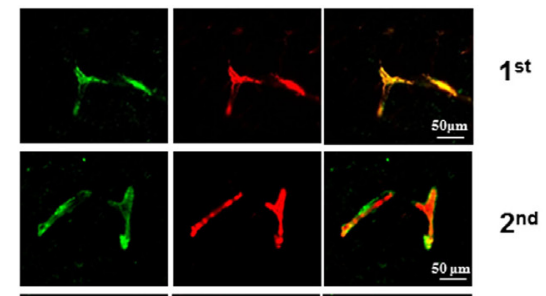

9 months
+
Anesthesia/surgery
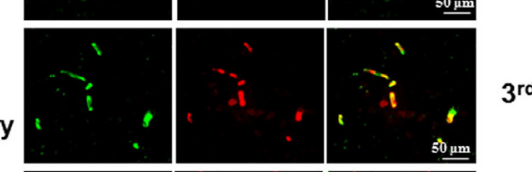

18 months
+
Anesthesia/surgery
18 months
18 months
+
Anesthesia/surgery
+

IL-6 antibody
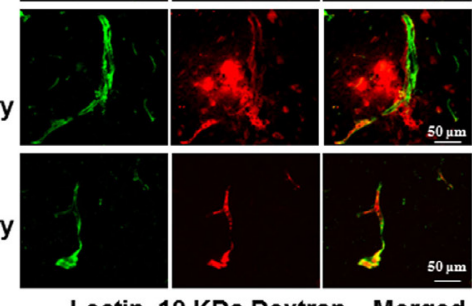

(a)

(b)

(c)

C

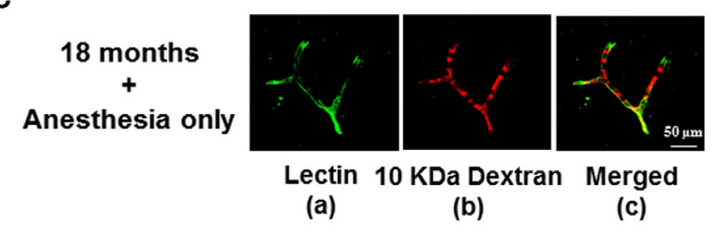

D

\section{9 month IL-6 KO $+$ control \\ 9 month IL-6 Ko}

Anesthesia/surgery

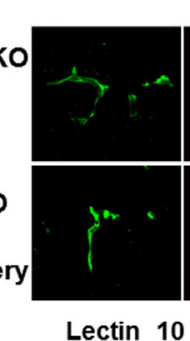

(a)

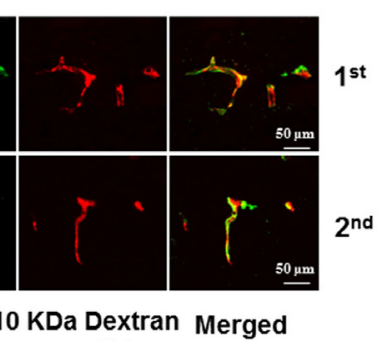

(b)

(c)

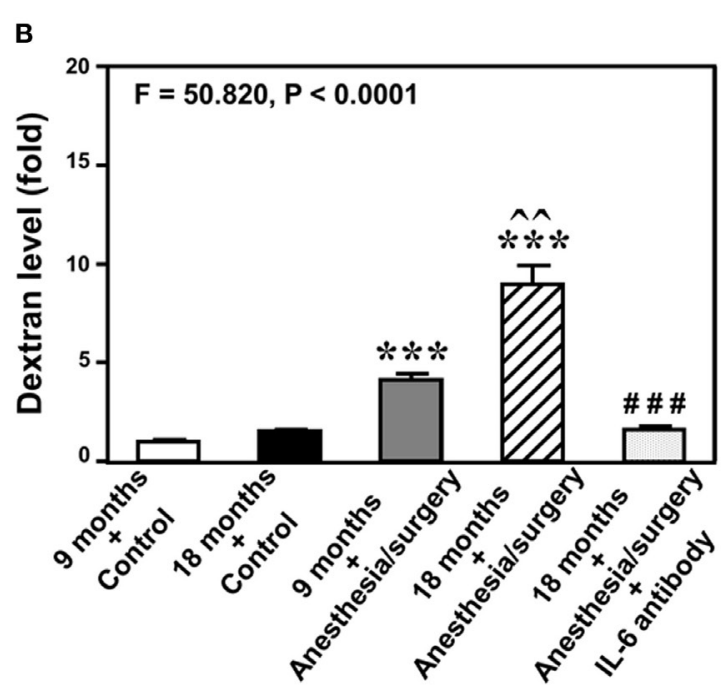

E

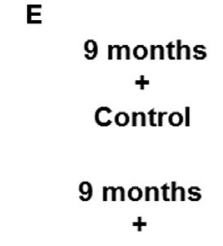

Anesthesia/surgery
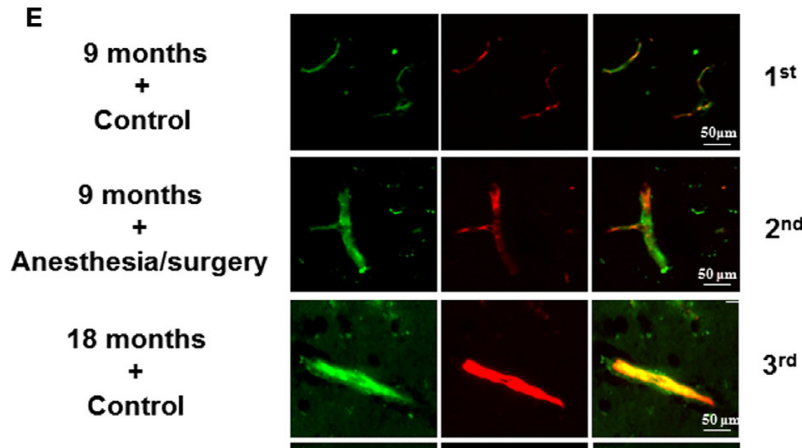

18 months

Anesthesia/surgery
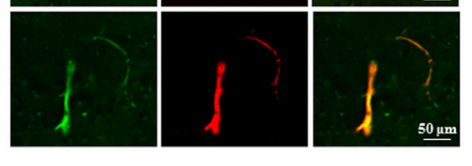

$3^{\text {rd }}$

Lectin $70 \mathrm{KDa}$ Dextran Merged

(a)

(c)

FIGURE 2 | Anesthesia/surgery increases blood-brain barrier permeability of dextran in mice in an age-associated manner. (A) Immunostaining of blood vessels (lectin, green, column a) and dextran (10-kDa dextran, red, column b) of the brain section following the control condition in 9-month-old mice (the first row), the control condition in 18-month-old mice (the second row), the anesthesia/surgery in 9-month-old mice (the third row), the anesthesia/surgery in 18-month-old mice (the fourth row), and the anesthesia/surgery in 18-month-old mice pre-treated with IL-6 antibody (the fifth row). Column $c$ is the merged image of columns a and $b$. The red spots (non-overlap area) in column $c$ indicate the dextran that is not inside the blood vessel (extravascular dextran). $N=$ total of 90 slides from 3 mice in each group. (B) Quantification of the immunostaining images shows that the anesthesia/surgery in 9-month-old mice (gray bar) increases the extravascular dextran level in the mouse brain tissues as compared to that in the control condition in 9-month-old mice (white bar). The anesthesia/surgery in 18-month-old mice (net bar) increases extravascular dextran level in the mouse brain as compared to that in the control condition in 18-month-old mice (black bar) and that in anesthesia/surgery condition in 9-month-old-mice (gray bar). Treatment with IL-6 antibody (dot bar) attenuates the anesthesia/surgery-induced increase in the extravascular dextran level in the brain tissues of 18-month-old mice (net bar). (C) Immunostaining of blood vessels (lectin, green, column a) and dextran (10-kDa dextran, red, column b) of the brain section following anesthesia only in one 18-month-old mouse. Column $c$ is the merged image of columns a and $b$. Anesthesia only does not increase the extravascular dextran level in the brain tissues of the 18-month-old mouse. The image represents one mouse. The studies were repeated twice in another two mice. (D) Immunostaining of blood vessels (lectin, green, column a) and dextran (10-kDa dextran, red, column $b$ ) of the brain section following anesthesia/surgery in one 9-month-old IL-6 gene knockout mouse. Column $c$ is the merged image of columns $a$ and $b$. The red spots (non-overlap area) in column $c$ indicate the dextran that is not inside the blood vessel (extravascular dextran). Anesthesia/surgery does not significantly increase the extravascular dextran level in the brain tissues of the 9-month-old IL-6 gene knockout mouse. The study was repeated in another mouse. (E) Immunostaining of blood vessels (lectin, green color, column a) and 70-kDa dextran (red, column b) of the brain section following the control condition in 9-month-old mice (the first row), the anesthesia/surgery in 9-month-old mice (the second row), the control condition in 18-month-old mice (the third row), and the anesthesia/surgery in 18-month-old mice (the fourth row). Column $c$ is the merged image of columns $a$ and $b$. The red spots (non-overlap area) in column $c$ indicate the 70-kDa dextran that is not inside the blood vessel (extravascular dextran). The anesthesia/surgery does not significantly increase the extravascular 70-kDa dextran level in the brain tissues of the 9-month-old mouse and 18-month-old mouse as compared to control condition. The image represents one mouse. The studies were repeated in another two mice. IL, interleukin. 


\section{Anesthesia/Surgery Increases Extravascular Level of Dextran in Mouse Brain}

Next, we performed spectrophotometer quantification to further assess whether anesthesia/surgery could increase the extravascular level of $10-\mathrm{kDa}$ dextran in brain tissues of mice. We found that the anesthesia/surgery increased the extravascular level of $10-\mathrm{kDa}$ dextran in the brain tissues of 9-month-old mice (Figure 3, gray bar) as compared to the control condition in the 9-month-old mice (Figure 3, white bar) $(P<0.01$, one-way ANOVA and Bonferroni test). Similarly, the anesthesia/surgery increased the extravascular level of $10-\mathrm{kDa}$ dextran in the brain tissues of 18-month-old mice (Figure 3, net bar) as compared to the control condition in the 18-month-old mice (Figure 3, black bar $)(P<0.01$, one-way ANOVA and Bonferroni test). However, anesthesia/surgery did not increase the extravascular level of 10-kDa dextran in the brain tissues of 9-month-old IL-6 KO mice (Figure 3 dot bar versus gray bar versus white bar) $(P<0.001$, one-way ANOVA and Bonferroni test). These data further suggest that the anesthesia/surgery is able to increase BBB permeability and the effects could be dependent on IL-6 level.

\section{Anesthesia/Surgery Increases Blood IL-6 Level in Mice}

Given the findings that the anesthesia/surgery might induce an IL-6-dependent increase in BBB permeability, next we asked

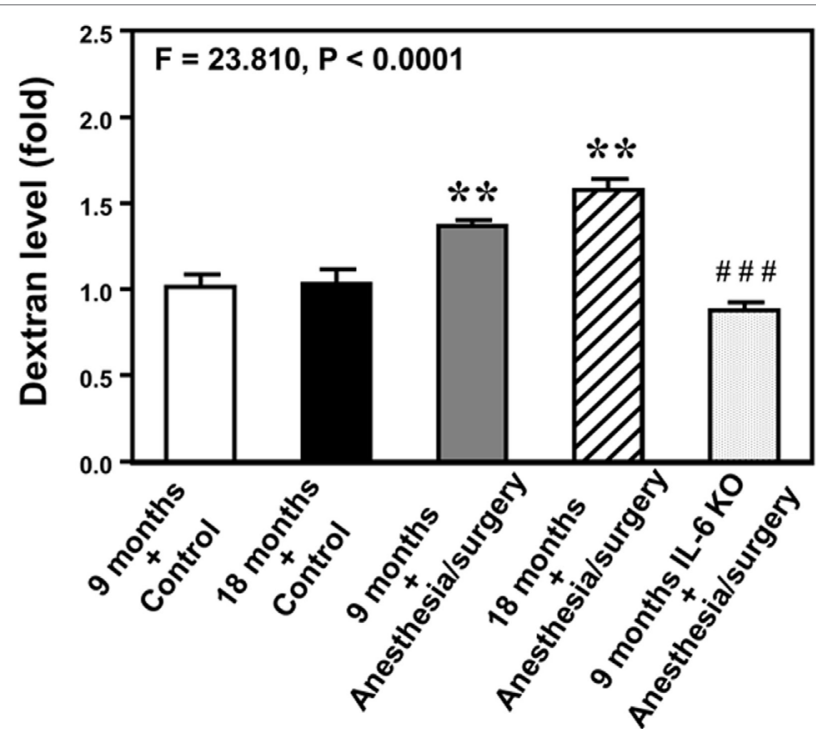

FIGURE 3 | Anesthesia/surgery increases blood-brain barrier permeability of dextran in mice. Spectrophotometric quantification of brain dextran (10 kDa) level. The anesthesia/surgery in 9-month-old mice (gray bar) increases brain dextran level as compared to that in the control condition of 9-month-old mice (white bar). Anesthesia/surgery in 18-month-old mice (net bar) increases brain dextran level as compared to that in the control condition of 18-monthold mice (black bar). Knockout of interleukin (IL)-6 gene (dot bar versus gray bar) attenuates the anesthesia/surgery-induced increase in dextran levels. $N=4$ in the control condition group and $N=5$ in the anesthesia/surgery group. whether the anesthesia/surgery could increase blood IL-6 level in the mice. We found that the anesthesia/surgery significantly increased blood IL-6 level as compared to control condition (left two bars) at 3 (middle two bars) and 6 (right two bars) hours after the anesthesia/surgery in both 9-month-old (black and net bar) and 18-month-old (gray and dot bar) mice $(F=13.36, P=0.0001$, one-way ANOVA, Figure 4). Note that the anesthesia/surgeryinduced a larger increase in blood IL-6 levels in the 18-month-old mice as compared to that in the 9-month-old mice at $3 \mathrm{~h}$ after the anesthesia/surgery (gray bar versus black bar, $P<0.05$ ). The anesthesia/surgery also induced a greater increase in blood IL-6 levels in the 18-month-old mice as compared to that in the 9-month-old mice at $6 \mathrm{~h}$ after the anesthesia/surgery (net bar versus dot bar). However, the difference did not reach to a statistically significant level. These data suggest that the anesthesia/surgery could induce an age-associated increase in blood IL-6 level in the mice, which would contribute to the anesthesia/surgery-induced increase in $\mathrm{BBB}$ permeability in the brain tissues of the mice.

\section{Anesthesia/Surgery Induces Cognitive Impairment in an Age-Associated Manner}

Given the findings that the anesthesia/surgery increased BBB permeability in an age-associated manner, next we investigated the functional relevance of these findings. Two-way ANOVA with repeated measurement showed no interaction of treatment (control condition and anesthesia/surgery) and time (days 1-7) on escape latency in the 9-month-old mice (Figure 5A, $F=0.300, P=0.937$ ). The anesthesia/surgery did not significantly change the platform crossing times (Figure 5C,

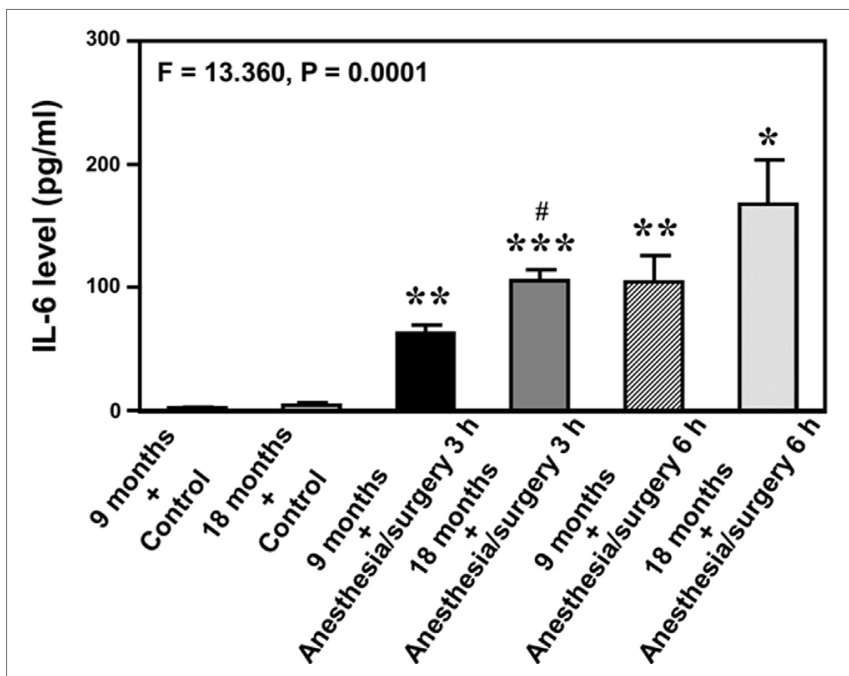

FIGURE 4 | Anesthesia/surgery increases blood IL-6 level in 9- and 18-month-old mice. The anesthesia/surgery increases blood IL-6 level in 9-month-old (black bar and net bar) and 18-month-old (gray bar and dot bar) mice at 3 (middle two bars) and 6 (right two bars) hours after the anesthesia/ surgery as compared to the control condition (left two bars). The anesthesia and surgery induces a significant increase in blood IL-6 levels in the 18-month-old mice as compared to that in the 9-month-old mice at 3 and $6 \mathrm{~h}$ after the anesthesia/surgery. $N=3$ in the control condition group and $N=3$ in the anesthesia/surgery group. IL, interleukin. 

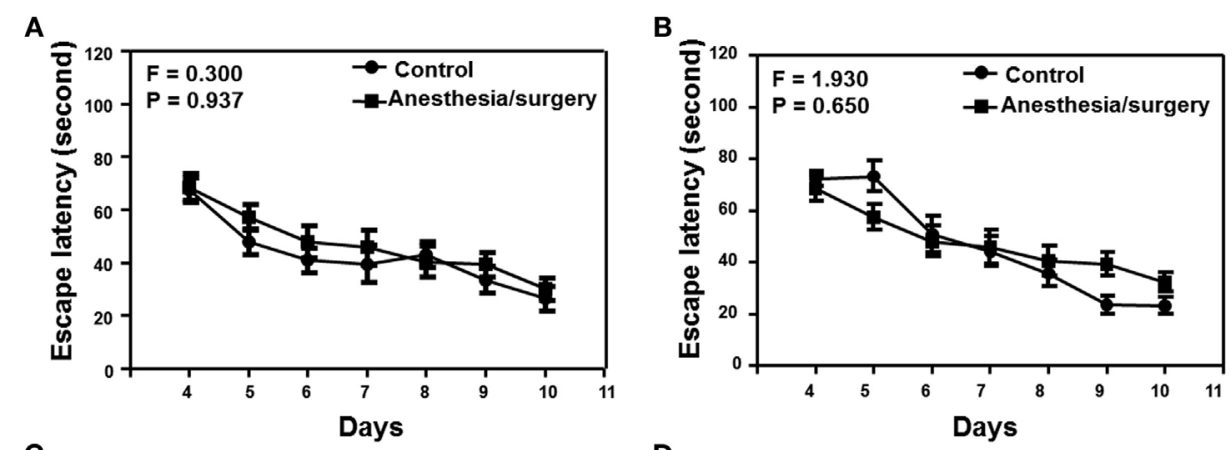

C

D
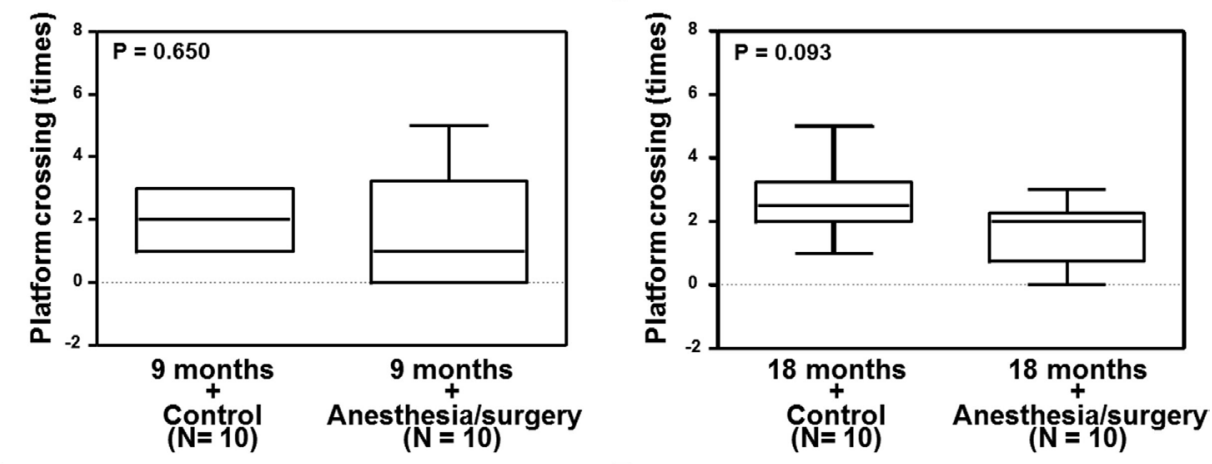

E

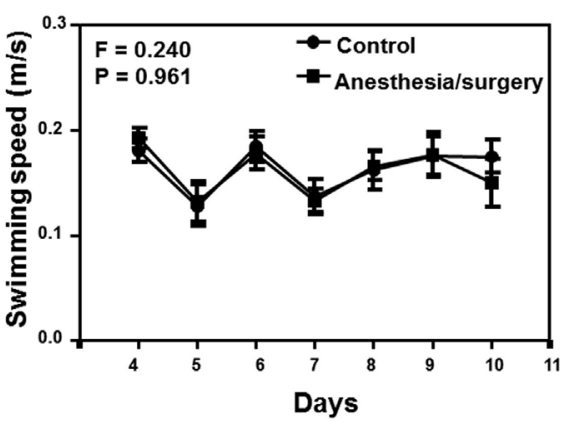

$\mathbf{F}$

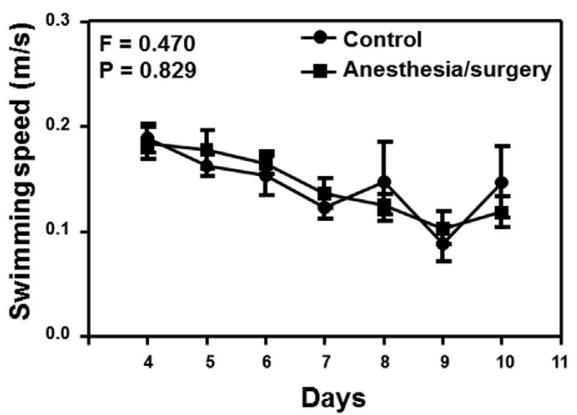

FIGURE 5 | Effects of anesthesia/surgery on cognitive function in 9- and 18-month-old mice tested in MWM. The anesthesia/surgery does not significantly change the escape latency (A), platform crossing times (C), and swimming speed (E) of MWM as compared to the control condition in the 9-month-old mice. The anesthesia/surgery does not significantly change the escape latency (B) and swimming speed (F) of MWM as compared to the control condition in the 18-monthold mice. However, the anesthesia/surgery induces a borderline increase $(P=0.093)$ in platform crossing times (D) of MWM as compared to the control condition in the 18-month-old mice. $N=10$ in the control condition group and $N=10$ in the anesthesia/surgery group. MWM, Morris water maze.

$P=0.464$, Mann-Whitney test) or swimming speed (Figure 5E, $F=0.240, P=0.961$, two-way ANOVA with repeated measurement) as compared to the control condition in the 9-month-old mice. Two-way ANOVA with repeated measurement showed no interaction of treatment (control condition and anesthesia/ surgery) and time (days 1-7) on escape latency in the 18-monthold mice (Figure 5B, $F=1.930, P=0.650$ ). The anesthesia/ surgery induced a borderline increase in the platform crossing times (Figure 5D, $P=0.093$, Mann-Whitney test) as compared to the control condition in the 18 -month-old mice. The anesthesia/surgery did not significantly change the swimming speed (Figure 5F, $F=0.240, P=0.961$, two-way ANOVA with repeated measurement) as compared to the control condition in the 18-month-old mice.
We found that the anesthesia/surgery did not significantly change the escape latency (Figure 6A), escape distance (Figure 6C), escape speed (Figure 6E), escape errors (Figure 6G), and time in target quadrant (Figure 6I) as compared to the control condition in the 9-month-old mice. However, the anesthesia/ surgery significantly increased the escape latency (Figure 6B, $P=0.0296$, Student's $t$-test) and escape distance (Figure 6D, $P<0.0001$, Student's $t$-test) as compared to the control condition in the 18-month-old mice. The anesthesia/surgery did not significantly change the escape speed (Figure 6F), escape errors (Figure 6H), and time in target quadrant (Figure 6J) as compared to the control condition in the 18-month-old mice. Taken together, these data suggest that the anesthesia/surgery could induce an age-associated cognitive impairment in mice. 


\section{Anesthesia/Surgery Decreases Levels of Cell Junction Proteins}

Previous studies in rodents have shown that BBB permeability is associated with the alteration of cell junction protein in cerebral endothelial cells [reviewed in Ref. (16)]. Given the findings that the anesthesia/surgery was able to increase BBB permeability to small, but not big, molecules, next, we compared the effects of the anesthesia/surgery on the levels of $\beta$-catenin, tight junction
A

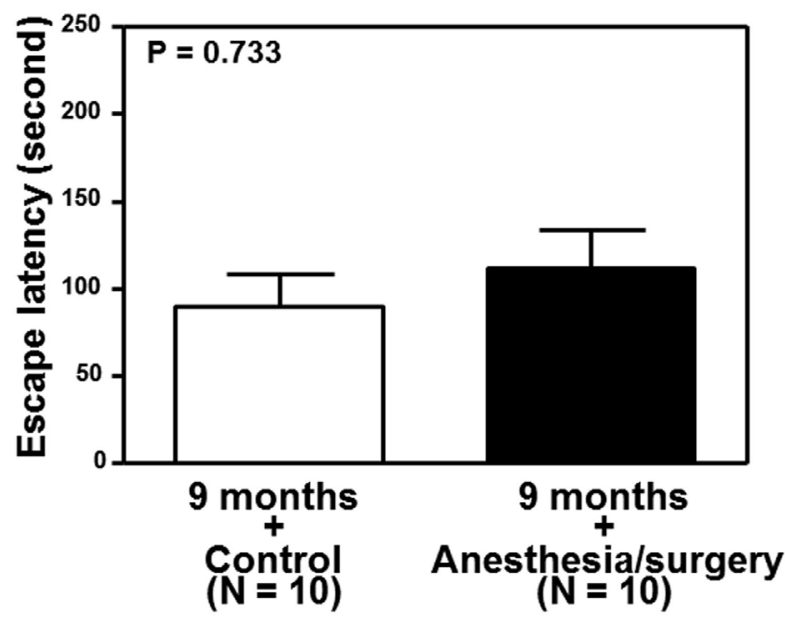

C

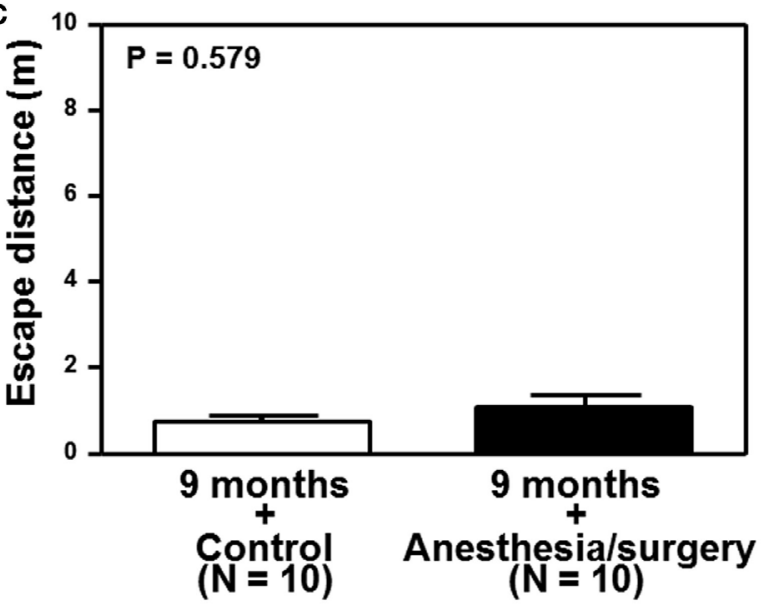

E

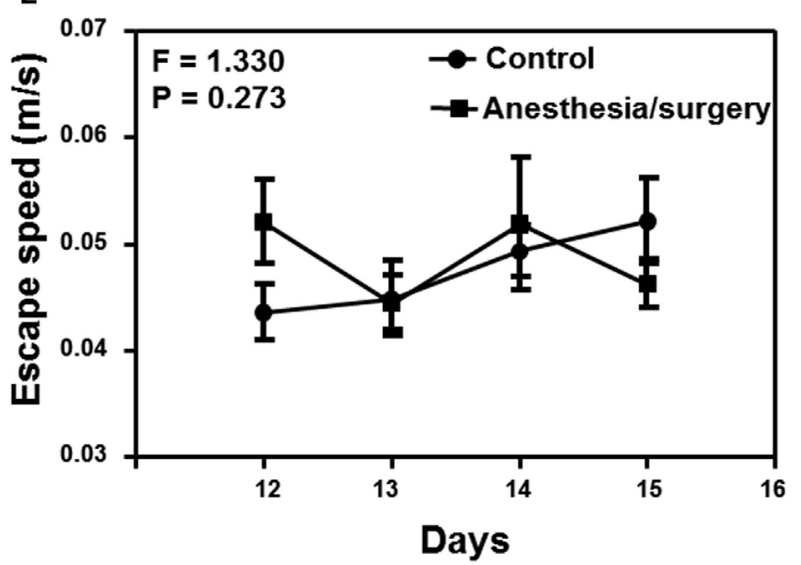

B

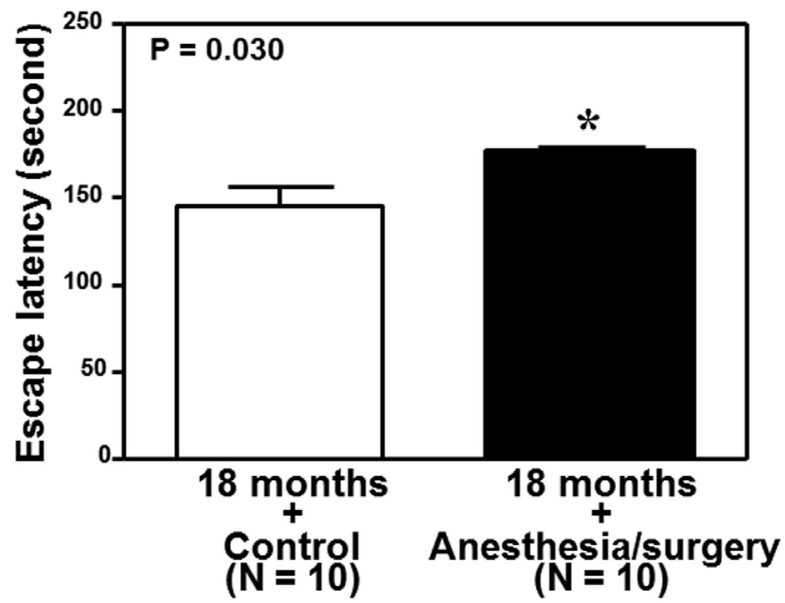

D

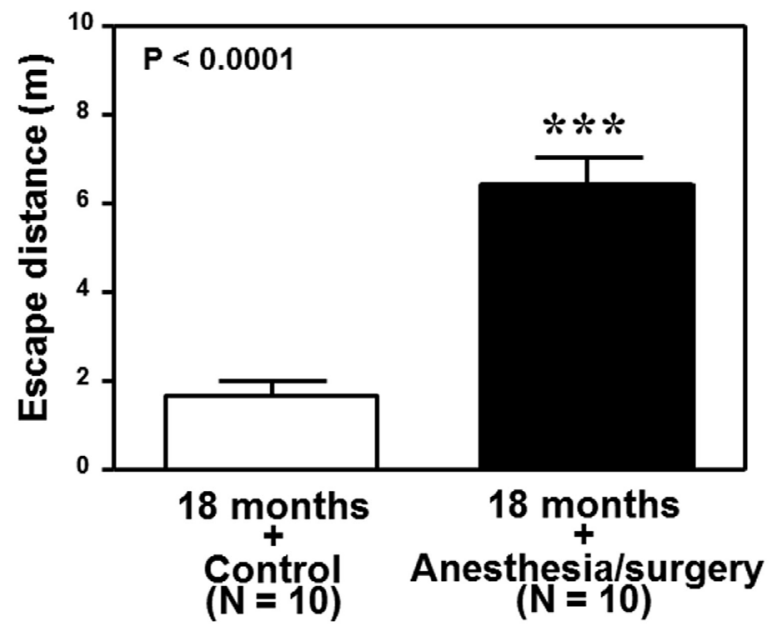

$\mathbf{F}$

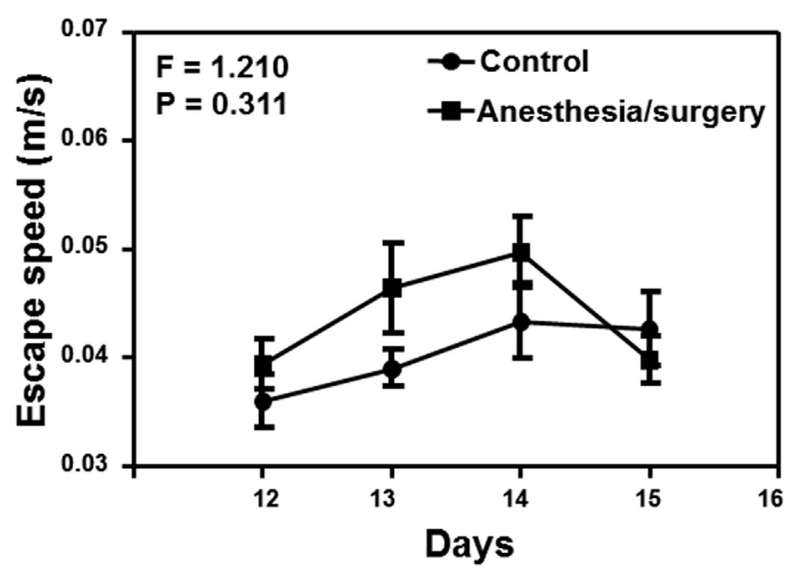




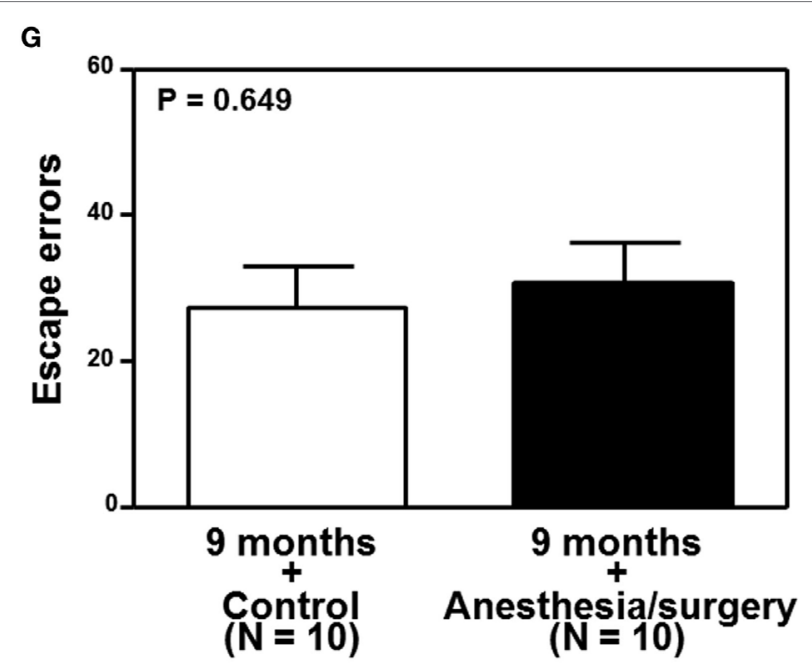

H
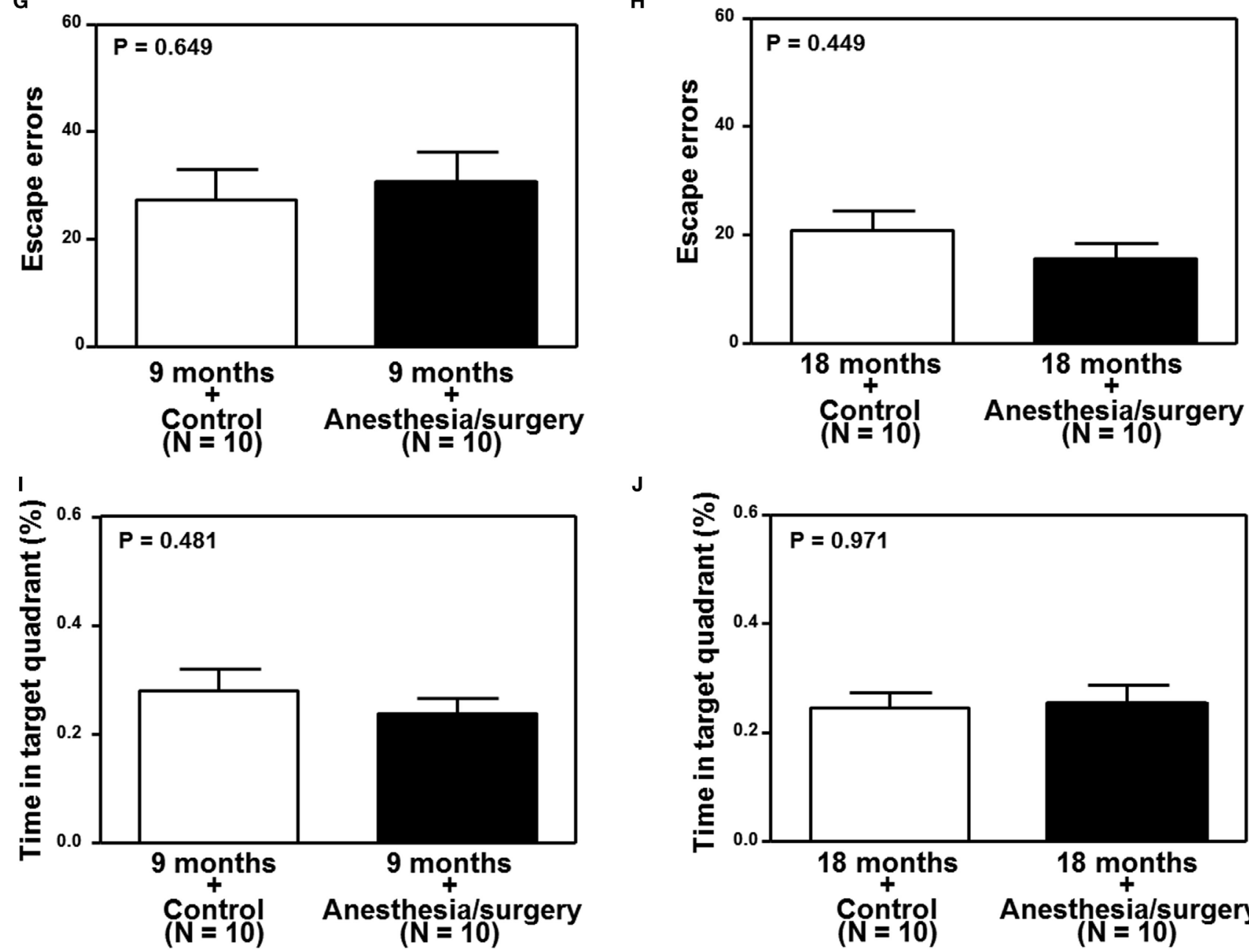

$\mathbf{J}$

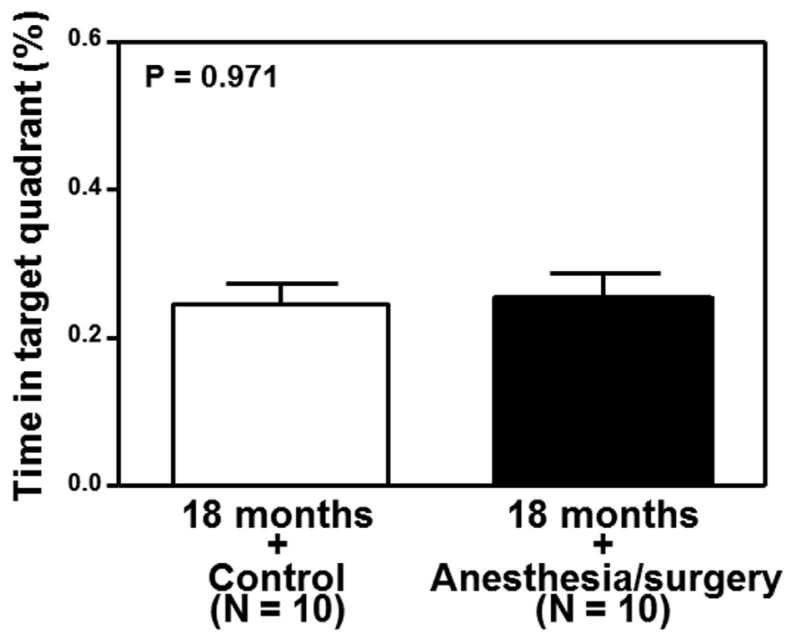

FIGURE 6 | Effects of anesthesia/surgery on cognitive function in 9- and 18-month-old mice tested in Barnes maze. The anesthesia/surgery does not significantly change the escape latency (A), escape distance (C), escape speed (E), escape errors (G), and time in target quadrant (I) of Barnes maze as compared to the control condition in the 9-month-old mice. However, in the 18-month-old mice, the anesthesia/surgery significantly increases escape latency (B) and escape distance (D) of Barnes maze as compared to the control condition. The anesthesia/surgery does not significantly change the escape speed (F), escape errors $\mathbf{( H )}$, and time in target quadrant $\mathbf{( J )}$ of Barnes maze as compared to the control condition in the 18-month-old mice. $\mathrm{N}=10$ in the control condition group and $N=10$ in the anesthesia/surgery group.

proteins claudin, occludin, and ZO-1, and adherent junction proteins VE-cadherin, E-cadherin, and p120-catenin in cortex and hippocampus of 18-month-old mice. Quantitative Western blot showed that the anesthesia/surgery significantly decreased the level of $\beta$-catenin in cortex $(F=15.280, P<0.0001$, oneway ANOVA, Figures 7A,B $)$ and hippocampus $(F=39.090$, $P<0.0001$, one-way ANOVA, Figures 7C,D) as compared to control condition at 6,12 , and $24 \mathrm{~h}$ after the anesthesia/surgery in 18-month-old mice. Moreover, quantitative Western blot showed that the anesthesia/surgery increased the phosphorylated $\beta$-catenin levels at 6,12 , and $24 \mathrm{~h}$ after the anesthesia/surgery as compared to control condition $(F=5.233, P=0.011$, oneway ANOVA, Figures $7 \mathbf{E}, \mathbf{F})$. Note that the antibody $(92 \mathrm{kDa}$, Cat: \#9561, 1:1,000 dilution, Cell signaling, Danvers, MA, USA) we used specifically detected the phosphorylated $\beta$-catenin (Ser33/37/Thr41) levels in the cytosol $(44,45)$. Finally, the anesthesia/surgery decreased levels of claudin as compared to control condition at 6,12 , and $24 \mathrm{~h}$ after the anesthesia/surgery in hippocampus of 18-month-old mice $(F=40.170, P<0.0001$, one-way ANOVA, Figures 7G,H).

Interestingly, the anesthesia/surgery did not significantly change the levels of the adherent junction proteins (VE-cadherin, E-cadherin, and p120-catenin) in cortex or hippocampus of 18-month-old mice as compared to the control condition at 6,12 , and $24 \mathrm{~h}$ after the anesthesia/surgery (Figure S1 in Supplementary Material). These data suggest that the anesthesia/surgery may specifically regulate the levels of tight junction proteins but not adherent junction proteins in present experiments. 


\section{IL-6 Antibody and KO of IL-6 Attenuates the Anesthesia/Surgery-Induced Reduction in the Levels of Cell Junction Proteins}

The 18-month-old mice received IL- 6 antibody $18 \mathrm{~h}$ before the anesthesia/surgery and the hippocampus tissues were harvested
$24 \mathrm{~h}$ after the anesthesia/surgery. Quantitative Western blot showed that the treatment of IL-6 antibody significantly attenuated the anesthesia/surgery-induced reduction in the levels of $\beta$-catenin $(F=7.420, P=0.009$, two-way ANOVA, Figures 8A,B), claudin $(F=10.310, P=0.009$, two-way ANOVA, Figures 8C,D), occlu$\operatorname{din}(F=10.340, P=0.009$, two-way ANOVA, Figures $8 \mathrm{E}, \mathbf{F})$, and ZO-1 $(F=23.280, P=0.0007$, two-way ANOVA, Figures $\mathbf{8 G}, \mathbf{H})$
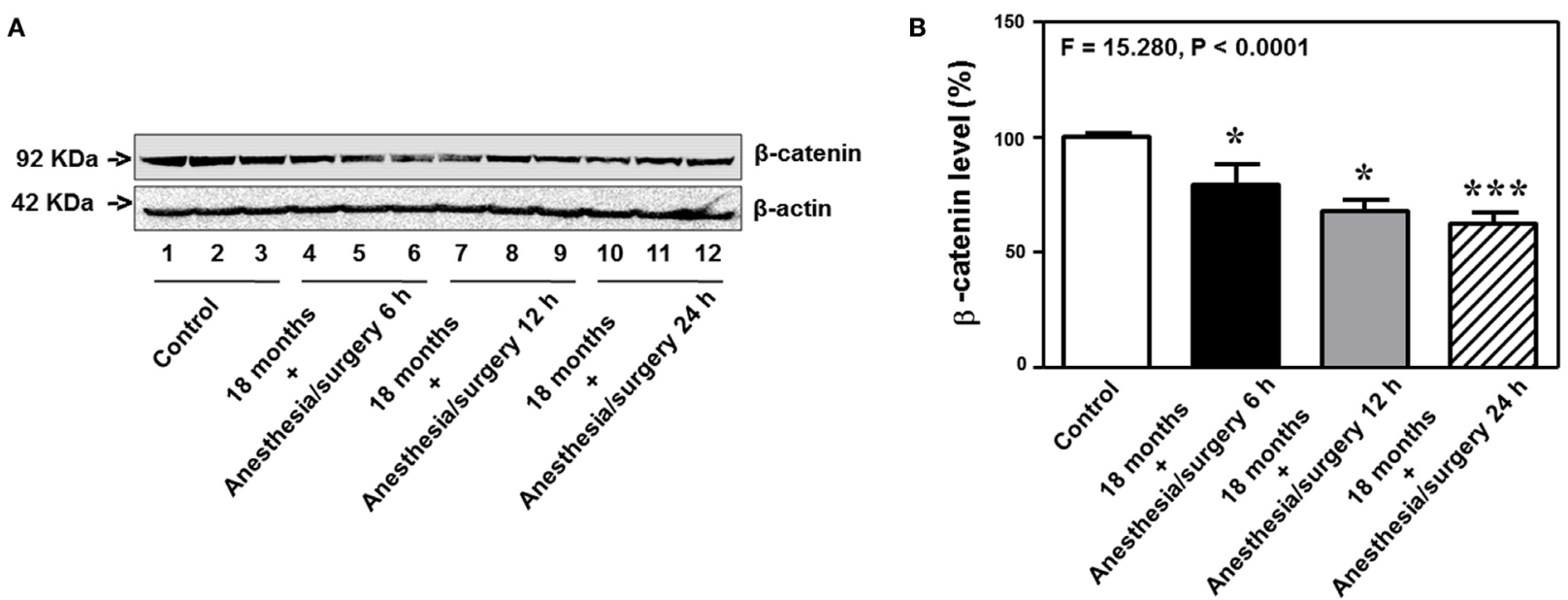

C

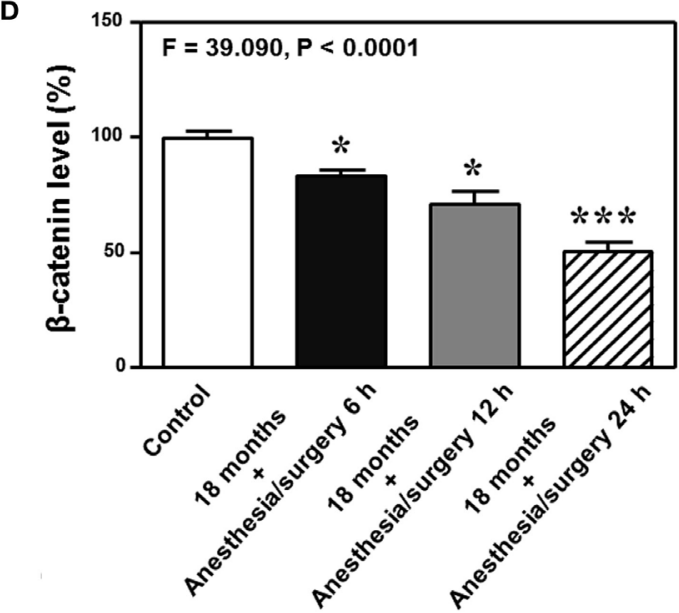

E

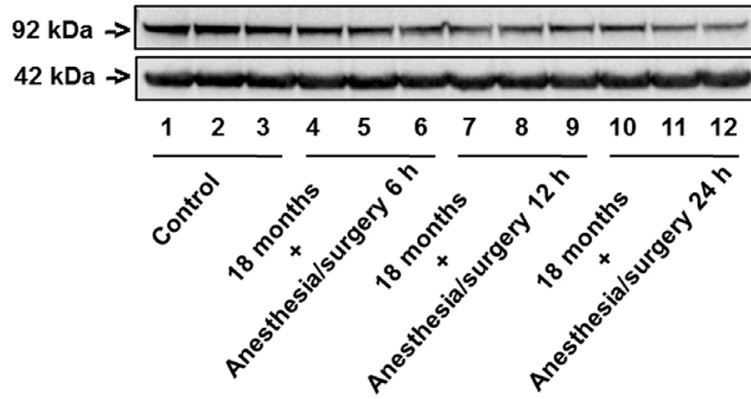

$\beta$-catenin

$\beta$-actin

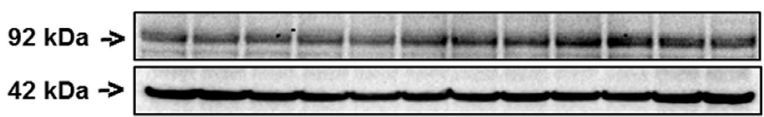

p- $\beta$-catenin

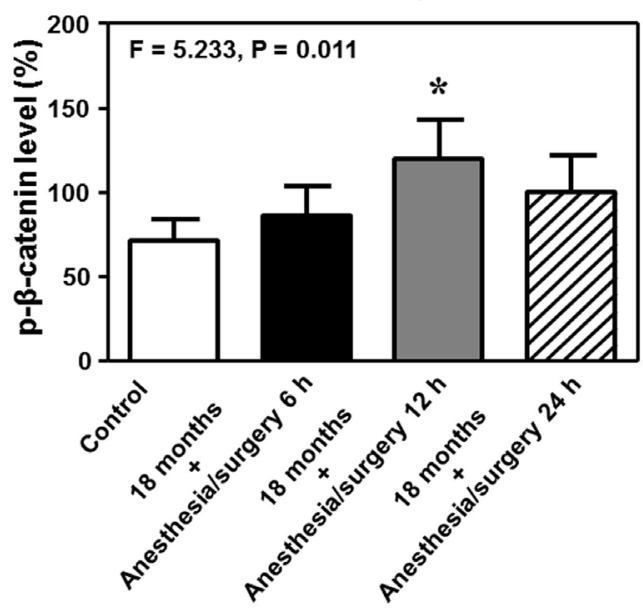

FIGURE 7 | Continued 

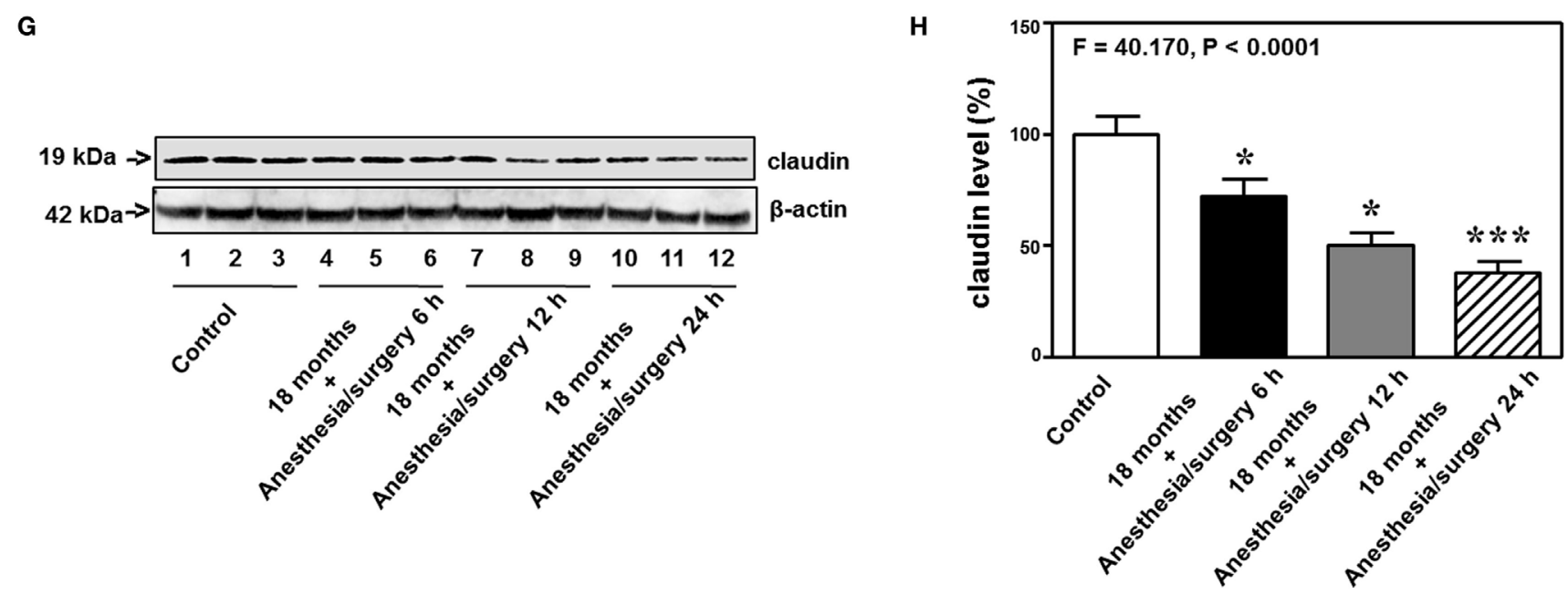

FIGURE 7 | Anesthesia/surgery decreases levels of cell junction proteins. The anesthesia/surgery decreases $\beta$-catenin levels in the cortex of 18-month-old mice at 6,12 , and $24 \mathrm{~h}$ after the anesthesia/surgery as compared to the control condition (A,B). The anesthesia/surgery decreases $\beta$-catenin levels in the hippocampus of 18-month-old mice at 6,12 , and $24 \mathrm{~h}$ after the anesthesia/surgery as compared to the control condition (C,D). The anesthesia/surgery increases the phosphorylated $\beta$-catenin levels in the hippocampus of 18-month-old mice at 6, 12, and $24 \mathrm{~h}$ after the anesthesia/surgery as compared to the control condition $\mathbf{( E , F ) . ~ T h e ~ a n e s t h e s i a / s u r g e r y ~ r e d u c e s ~ t h e ~ l e v e l ~ o f ~ c l a u d i n ~ i n ~ t h e ~ h i p p o c a m p u s ~ o f ~} 18$-month-old mice at 6,12 , and $24 \mathrm{~h}$ compared to control condition $\mathbf{( G , H ) . ~} \mathrm{N}=6$ in control or anesthesia/surgery group.

in the hippocampus of the 18-month-old mice. The fifth band on each of the Western blot image represents the level of $\beta$-catenin (Figure 8A), claudin (Figure 8C), occludin (Figure 8E), and ZO-1 (Figure 8G) obtained from one 18-month-old IL-6 KO mouse. Taken together, these data suggest that treatment of IL-6 antibody or KO of IL- 6 gene is able to attenuate the anesthesia/ surgery-induced reduction in the levels of cell junction proteins.

\section{DISCUSSION}

Anesthesia and surgery (anesthesia/surgery) in rodents have been shown to induce cognitive impairment [(1-10, 33), reviewed in Ref. (11)]. However, the underlying mechanisms still remain largely to be determined. Given the fact that BBB dysfunction could contribute to cognitive impairment $[(18,46-$ $48)$, reviewed in Ref. $(17,20)]$, we set out to investigate whether the anesthesia/surgery was able to induce BBB dysfunction, e.g., increase in $\mathrm{BBB}$ permeability and cognitive impairment in mice.

Dextran-tracer injection has been used to reveal BBB formation and function (15). We, therefore, employed dextran to assess the effects of the anesthesia/surgery on $\mathrm{BBB}$ function in our studies. The anesthesia/surgery induced BBB dysfunction as evidenced by the findings that the anesthesia/surgery increased the $\mathrm{BBB}$ permeability to $10-\mathrm{kDa}$ dextran in the brain tissues of mice (Figures 2A,B). Moreover, there was greater BBB permeability to the $10-\mathrm{kDa}$ dextran in the brain tissues of 18 -month-old mice than that in the brain tissues of 9-month-old mice following the anesthesia/surgery: row 3 versus row 4 in Figure 2A; and gray bar versus net bar in Figure 2B. Finally, IL-6 antibody (Figures 2A,B) and knockout of IL-6 gene (Figure 2D) attenuated the anesthesia/ surgery-induced increase in $\mathrm{BBB}$ permeability to $10-\mathrm{kDa}$ dextran. The anesthesia/surgery may not induce the increase in $\mathrm{BBB}$ permeability to larger molecules, e.g., 70-kDa dextran. Finally, the anesthesia/surgery induced an age-associated increase in blood IL-6 levels (Figure 4). Collectively, these data support the hypothesis that the anesthesia/surgery induces an age-associated and IL-6 dependent increase in BBB permeability in mice.

Consistent with these data, we were able to show that the anesthesia/surgery induced cognitive impairment in the 18 , but not 9, month-old mice (Figures 5 and 6). The data suggest that the anesthesia/surgery might cause an age-associated BBB dysfunction, leading to the age-associated cognitive impairment in rodents, pending on further investigation.

Neuroinflammation has been suggested to contribute to postoperative delirium [reviewed in Ref. (49)] and postoperative cognitive dysfunction [reviewed in Ref. (17)]. Specifically, IL-6 has been reported to be associated with learning and memory impairment in animals (50-52), cognitive dysfunction (53), mild cognitive impairment (54), and delirium in patients (55). In the current studies, we found that the anesthesia/surgery-induced an age-associated increase in blood IL-6 level (Figure 4); as well as an age-associated and IL-6-dependent BBB dysfunction (Figures 2 and 3). These findings further support the role of IL-6 in the neurotoxicity associated with anesthesia and surgery; and suggest that IL-6 may contribute to postoperative delirium and postoperative cognitive dysfunction via the impairment of $\mathrm{BBB}$ function. Finally, these results postulate the hypothesis that the accumulated IL-6, induced by the anesthesia and/or surgery, could attack the BBB, leading to BBB dysfunction.

The human IL-6 protein has 184 amino acids plus a 28-amino-acid-hydrophobic signal sequence (56). Blood IL-6 can be generated by circulating myeloid or lymphoid cells, or can be released from gut, liver, wound, muscle, and other local tissues [reviewed in Ref. (57)]. Specifically, IL-6 is produced in 
A
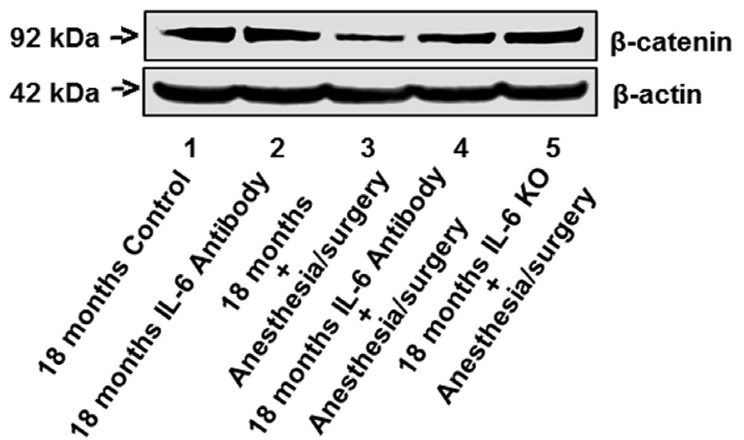

C

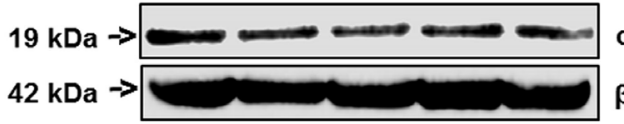

claudin

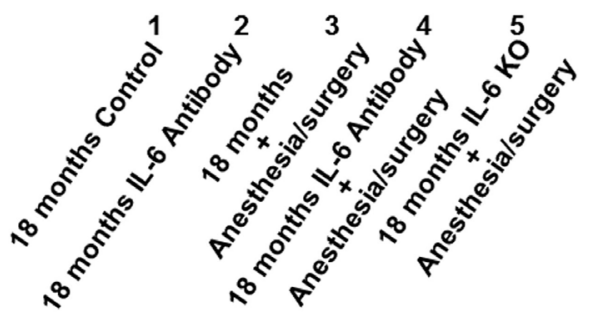

E

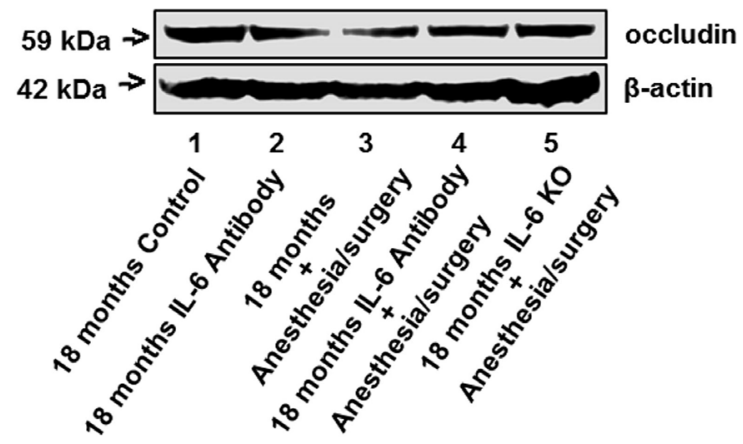

B

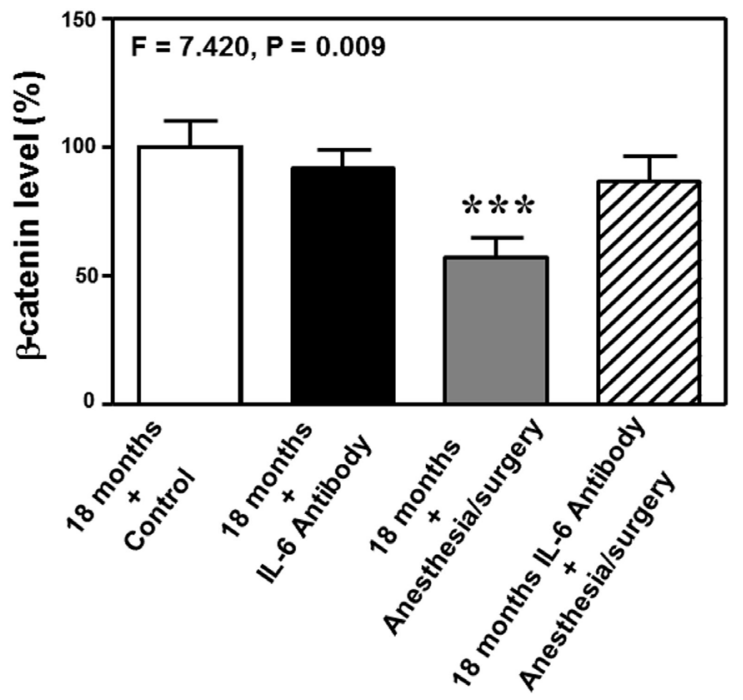

D

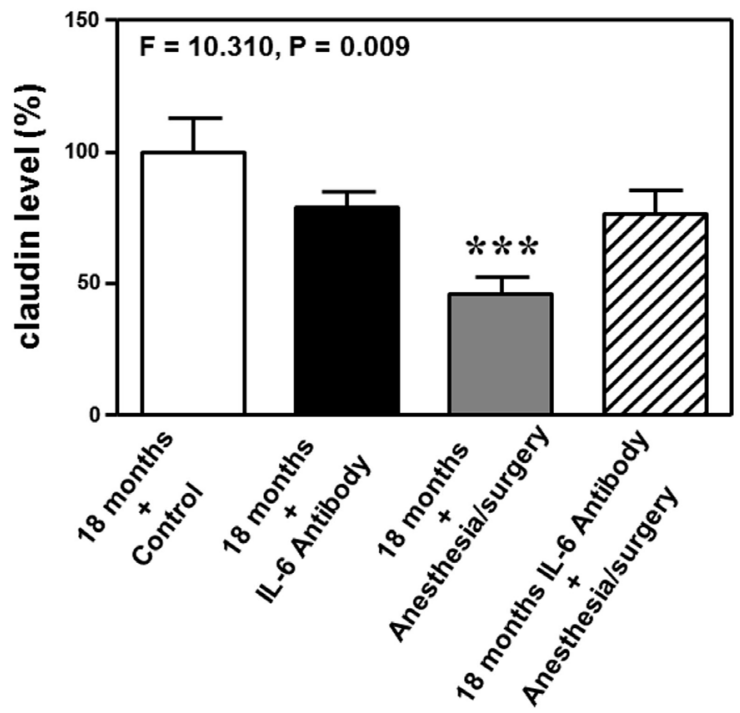

$\mathbf{F}$

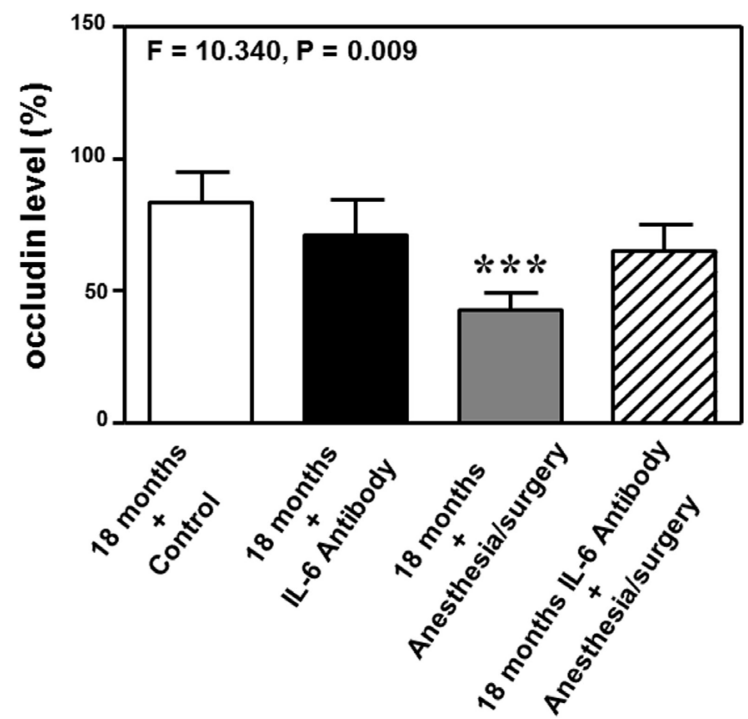




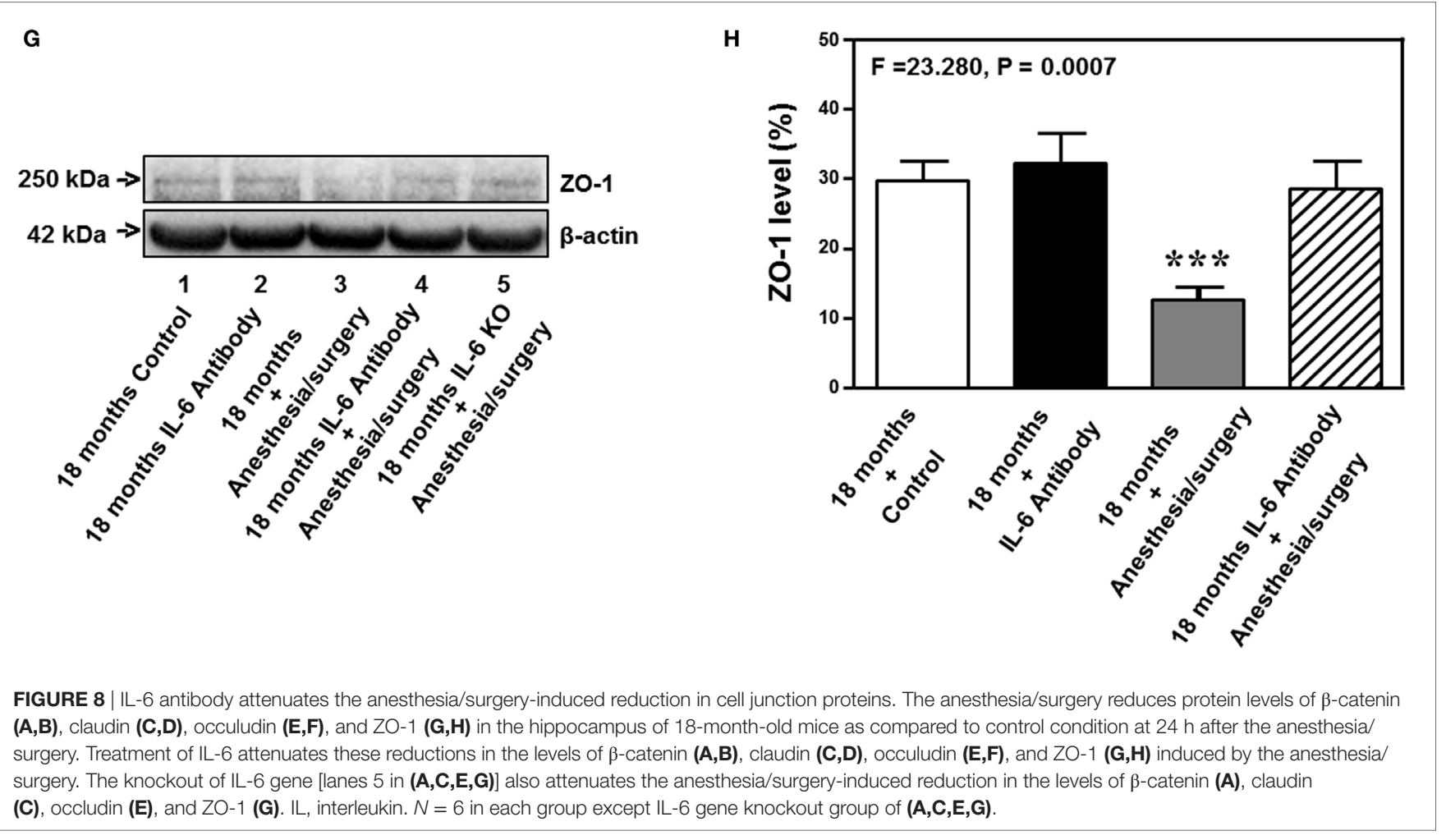

peripheral blood leukocytes, spleen, liver, kidney, and intestine $(58,59)$ and the induction of IL- 6 generation is in nearly every human tissues and cells [reviewed in Ref. (57)]. A recent study showed that blood monocyte was able to generate IL-6 (60). The data from our current studies have established a system and shown that the anesthesia/surgery can increase blood IL-6 levels and may induce an IL-6-dependent increase in BBB permeability. However, the underlying mechanisms of such findings remain largely unknown. The future studies should assess whether injection of IL- 6 is able to increase the BBB permeability in IL-6 KO mice. The future studies should also test a hypothesis that the anesthesia/surgery-induced increase in IL-6 may regulate junction protein levels, BBB permeability, and cognition in mice via cellular signal transduction, e.g., Wnt signaling pathway.

Anesthesia/surgery did not increase the BBB permeability of $70-\mathrm{kDa}$ dextran (Figure 2E). The exact reason why the anesthesia/surgery increased the BBB permeability to $10-\mathrm{kDa}$ dextran, but not $70-\mathrm{kDa}$ dextran, is not known at the present time. The molecular weights of $70-\mathrm{kDa}$ dextran are larger than that of $10-\mathrm{kDa}$ dextran, it is conceivable that the anesthesia/surgery might only increase $\mathrm{BBB}$ permeability to small molecules (e.g., dextran, $10 \mathrm{kDa}$ ), but not large molecules (e.g., dextran, $70 \mathrm{kDa}$ ).

There are other studies that also demonstrate that anesthesia and surgery induce BBB dysfunction. Dittmar et al. showed that anesthetic isoflurane, administered after hypoxia, was able to induce apoptosis of endothelial cells in vitro (61). These findings suggest that isoflurane might damage BBB (61). Acharya et al. reported that anesthetic sevoflurane, but not isoflurane, was able to induce an aging-linked BBB compromise in rats, potentially leading to postoperative cognitive decline and later dementia (62). However, isoflurane was also reported to lead to hippocampal $\mathrm{BBB}$ compromise through changes in ultrastructure and occludin tight junction protein expression in aged rats (63). Finally, surgery (splenectomy) under anesthesia (2-3\% isoflurane) was able to increase the BBB permeability measured with IgG immunohistochemistry in aged (22- to 23-month-old) rats (64). Consistent with these findings, the data from the current studies demonstrated that the surgery plus anesthesia (1.4\% isoflurane up to $2 \mathrm{~h}$ ) increased the BBB permeability to $10-\mathrm{kDa}$ dextran. However, the data from the current studies further showed that minor surgery (opening and closing of abdominal cavity) under the anesthesia could induce an age-associated BBB dysfunction in mice (Figures 2 and 3). More importantly, the results from the current studies suggest that the anesthesia/surgery was able to selectively increase the BBB permeability to $10-\mathrm{kDa}$ dextran, but not to $70-\mathrm{kDa}$ dextran (Figure 2E). Finally, the findings from the current studies suggest that the anesthesia/surgery-induced increase in BBB permeability was dependent on IL-6 (Figures 2D and 3). The future studies will use the established system (the anesthesia/surgery-induced $\mathrm{BBB}$ permeability) to study whether $\mathrm{BBB}$ dysfunction contributes to postoperative cognitive dysfunction and postoperative delirium.

We found that the anesthesia/surgery was able to reduce the levels of tight junction protein claudin, occludin, and $\mathrm{ZO}-1$ (Figures 7 and 8), but not adherent junction protein VE-cadherin, E-cadherin, and p120-catenin (Figure S1 in Supplementary Material). These data suggest that the anesthesia/surgery may selectively impair tight junction, but not adherent junction, 
leading to the increase in $\mathrm{BBB}$ permeability to small molecule, e.g., 10-kDa dextran, but not big molecule, e.g., 70-kDa dextran.

Interestingly, the anesthesia/surgery decreased level of $\beta$-catenin. $\beta$-catenin exists in three locations: cell membrane, cytosol, and nucleus $(65,66)$. The cell membrane $\beta$-catenin is one of the adherent junction proteins. However, the findings that the anesthesia/surgery increased the levels of phosphorylated $\beta$-catenin (Ser33/37/Thr41) suggest that the anesthesia/ surgery may specifically decreased the levels of cytosol $\beta$-catenin, because the antibody (92 kDa, Cat: \#9561, 1:1,000 dilution, Cell signaling, Danvers, MA, USA) we used in the current experiment specifically detected the phosphorylated $\beta$-catenin (Ser33/37/ Thr41) levels in the cytosol (44). Nevertheless, it is still possible that the anesthesia/surgery could also regulate cell membrane and nucleus $\beta$-catenin. The future studies should specifically assess whether the anesthesia/surgery can also change the levels of cell membrane and nucleus $\beta$-catenin.

Taken together, the data obtained from the current studies suggest a hypothesized pathway that the anesthesia/surgery can increase plasma IL-6 levels, which regulate the metabolism of cytosol $\beta$-catenin, leading to reductions in the levels of tight junction proteins and increase in $\mathrm{BBB}$ permeability to small molecule. Consequently, the BBB dysfunction leads to cognitive impairment.

Recent studies have shown that CX3CR1+ monocytes can regulate learning and learning-dependent dendritic spine remodeling via TNF- $\alpha$ following infection with poly (I:C), a synthetic analog of double-stranded RNA (60). These data suggest that innate immune-cell activation may contribute to cognitive impairment. Thus, our future studies should include the investigation of the role of CX3CR1+ monocytes on the anesthesia/ surgery-induced changes in BBB permeability, levels of junction protein, and cognition in mice.

There are several limitations of the current studies. First, we only assessed the effects of the anesthesia/surgery on BBB permeability in cortex of the mice. The effects of the anesthesia/ surgery on $\mathrm{BBB}$ permeability in different brain regions (e.g., hippocampus) of the mice could be different. However, the outcomes from the current studies have established a system, which would be used to study the effects of anesthesia and/or surgery on $\mathrm{BBB}$ permeability in other brain regions. Second, our present study cannot define cellular sources and targets of the plasma IL-6. What cells release IL-6 and how this affects cells in the neurovascular unit warrant further investigation. Third, we did not use littermate controls for IL- $6 \mathrm{KO}$ mice throughout the experiments. We will use the littermate controls for IL-6 KO mice in the future investigation. Finally, we only assessed the effects of the anesthesia/surgery on BBB permeability in cortex to establish a system in the current studies. In the future investigations, we will use the established system to determine the effects of the anesthesia/surgery on BBB permeability in other brain regions (e.g., hippocampus) and the potential association with the observed behavioral changes.
In conclusion, the current studies mainly established a system in adult and older mice to study the effects of abdominal surgery under isoflurane anesthesia (anesthesia/surgery) on BBB permeability and behavioral changes. The data only suggest that the anesthesia/surgery may increase the BBB permeability to $10-\mathrm{kDa}$ dextran, but not $70-\mathrm{kDa}$ dextran, in the cortex of mice. This anesthesia/surgery-induced increase in the BBB permeability to dextran could be dependent on IL- 6 and might be greater in older mice (e.g., 18-month-old mice). Moreover, the anesthesia/surgery induced an age-associated cognitive impairment in the mice. Given the fact that BBB dysfunction is associated with cognitive impairment, the results from the current studies suggest that the anesthesia/surgery would induce postoperative delirium and cognitive impairment by damaging BBB function, pending further investigation. These findings would promote further studies of the BBB-associated underlying mechanisms of postoperative delirium and postoperative cognitive dysfunction.

\section{ETHICS STATEMENT}

All experiments were performed in accordance with the National Institutes of Health guidelines and regulations. The animal protocol was approved by the Massachusetts General Hospital (Boston, MA, USA) Standing Committee on the Use of Animals in Research and Teaching.

\section{AUTHOR CONTRIBUTIONS}

ZX, SY, CG, GY, YS, YZ, XF, and EL conceived and designed the project. SY, CG, EM, EE, YD, and YZ performed all the experiments and prepared the figures. ZX, SY, and CG wrote the manuscript. All authors reviewed the manuscript.

\section{ACKNOWLEDGMENTS}

This research was supported by R01GM088801, R01AG041274 and R01HD086977 (to ZX) and R01GM107469 (to GY) from National Institutes of Health, Bethesda, MD, USA. The costs of isoflurane and EMLA were generously provided by the Department of Anesthesia, Critical Care and Pain Medicine at Massachusetts General Hospital. The studies were performed in Massachusetts General Hospital and Harvard Medical School, Boston, MA, USA. YS was partially supported by 81571034 from the National Natural Science Foundation of China. CG was partially supported by 81600054 from the National Natural Science Foundation of China.

\section{SUPPLEMENTARY MATERIAL}

The Supplementary Material for this article can be found online at http://journal.frontiersin.org/article/10.3389/fimmu.2017.00902/ full\#supplementary-material. 


\section{REFERENCES}

1. Wan Y, Xu J, Ma D, Zeng Y, Cibelli M, Maze M. Postoperative impairment of cognitive function in rats: a possible role for cytokine-mediated inflammation in the hippocampus. Anesthesiology (2007) 106(3):436-43. doi:10.1097/00000542-200703000-00007

2. Wan Y, Xu J, Meng F, Bao Y, Ge Y, Lobo N, et al. Cognitive decline following major surgery is associated with gliosis, beta-amyloid accumulation, and tau phosphorylation in old mice. Crit Care Med (2010) 38(11):2190-8. doi:10.1097/CCM.0b013e3181f17bcb

3. Cibelli M, Fidalgo AR, Terrando N, Ma D, Monaco C, Feldmann M, et al. Role of interleukin-1beta in postoperative cognitive dysfunction. Ann Neurol (2010) 68(3):360-8. doi:10.1002/ana.22082

4. Terrando N, Rei Fidalgo A, Vizcaychipi M, Cibelli M, Ma D, Monaco C, et al. The impact of IL-1 modulation on the development of lipopolysaccharideinduced cognitive dysfunction. Crit Care (2010) 14(3):R88. doi:10.1186/ cc9019

5. Bianchi SL, Tran T, Liu C, Lin S, Li Y, Keller JM, et al. Brain and behavior changes in 12-month-old Tg2576 and nontransgenic mice exposed to anesthetics. Neurobiol Aging (2008) 29(7):1002-10. doi:10.1016/j.neurobiolaging. 2007.02.009

6. Xu Z, Dong Y, Wang H, Culley DJ, Marcantonio ER, Crosby G, et al. Agedependent postoperative cognitive impairment and Alzheimer-related neuropathology in mice. Sci Rep (2014) 4:3766. doi:10.1038/srep03766

7. Xu Z, Dong Y, Wang H, Culley DJ, Marcantonio ER, Crosby G, et al. Peripheral surgical wounding and age-dependent neuroinflammation in mice. PLoS One (2014) 9(5):e96752. doi:10.1371/journal.pone.0096752

8. Zhang Y, Xu Z, Wang H, Dong Y, Shi HN, Culley DJ, et al. Anesthetics isoflurane and desflurane differently affect mitochondrial function, learning, and memory. Ann Neurol (2012) 71(5):687-98. doi:10.1002/ana.23536

9. Saab BJ, Maclean AJ, Kanisek M, Zurek AA, Martin LJ, Roder JC, et al. Shortterm memory impairment after isoflurane in mice is prevented by the alpha5 gamma-aminobutyric acid type A receptor inverse agonist L-655,708. Anesthesiology (2010) 113(5):1061-71. doi:10.1097/ALN.0b013e3181f56228

10. Peng M, Zhang C, Dong Y, Zhang Y, Nakazawa H, Kaneki M, et al. Battery of behavioral tests in mice to study postoperative delirium. Sci Rep (2016) 6:29874. doi:10.1038/srep29874

11. Vutskits L, Xie Z. Lasting impact of general anaesthesia on the brain: mechanisms and relevance. Nat Rev Neurosci (2016) 17(11):705-17. doi:10.1038/ nrn.2016.128

12. Li CH, Shyu MK, Jhan C, Cheng YW, Tsai CH, Liu CW, et al. Gold nanoparticles increase endothelial paracellular permeability by altering components of endothelial tight junctions, and increase blood-brain barrier permeability in mice. Toxicol Sci (2015) 148(1):192-203. doi:10.1093/toxsci/kfv176

13. Saunders NR, Liddelow SA, Dziegielewska KM. Barrier mechanisms in the developing brain. Front Pharmacol (2012) 3:46. doi:10.3389/fphar.2012.00046

14. Siegenthaler JA, Sohet F, Daneman R. 'Sealing off the CNS': cellular and molecular regulation of blood-brain barriergenesis. Curr Opin Neurobiol (2013) 23(6):1057-64. doi:10.1016/j.conb.2013.06.006

15. Ben-Zvi A, Lacoste B, Kur E, Andreone BJ, Mayshar Y, Yan H, et al. Mfsd2a is critical for the formation and function of the blood-brain barrier. Nature (2014) 509(7501):507-11. doi:10.1038/nature13324

16. Zhao Z, Nelson AR, Betsholtz C, Zlokovic BV. Establishment and dysfunction of the blood-brain barrier. Cell (2015) 163(5):1064-78. doi:10.1016/j. cell.2015.10.067

17. Terrando N, Brzezinski M, Degos V, Eriksson LI, Kramer JH, Leung JM, et al. Perioperative cognitive decline in the aging population. Mayo Clin Proc (2011) 86(9):885-93. doi:10.4065/mcp.2011.0332

18. Zlokovic BV. The blood-brain barrier in health and chronic neurodegenerative disorders. Neuron (2008) 57(2):178-201. doi:10.1016/j.neuron.2008. 01.003

19. Wardlaw JM, Doubal F, Armitage P, Chappell F, Carpenter T, Munoz Maniega S, et al. Lacunar stroke is associated with diffuse bloodbrain barrier dysfunction. Ann Neurol (2009) 65(2):194-202. doi:10.1002/ ana.21549

20. Zlokovic BV. Neurovascular pathways to neurodegeneration in Alzheimer's disease and other disorders. Nat Rev Neurosci (2011) 12(12):723-38. doi:10.1038/nrn3114
21. Wardlaw JM, Sandercock PA, Dennis MS, Starr J. Is breakdown of the bloodbrain barrier responsible for lacunar stroke, leukoaraiosis, and dementia? Stroke (2003) 34(3):806-12. doi:10.1161/01.STR.0000058480.77236.B3

22. Girard TD, Jackson JC, Pandharipande PP, Pun BT, Thompson JL, Shintani AK, et al. Delirium as a predictor of long-term cognitive impairment in survivors of critical illness. Crit Care Med (2010) 38(7):1513-20. doi:10.1097/CCM.0b013e3181e47be1

23. Guenther U, Popp J, Koecher L, Muders T, Wrigge H, Ely EW, et al. Validity and reliability of the CAM-ICU flowsheet to diagnose delirium in surgical ICU patients. J Crit Care (2010) 25(1):144-51. doi:10.1016/j.jcrc.2009.08.005

24. Ely EW, Shintani A, Truman B, Speroff T, Gordon SM, Harrell FE Jr, et al. Delirium as a predictor of mortality in mechanically ventilated patients in the intensive care unit. JAMA (2004) 291(14):1753-62. doi:10.1001/ jama.291.14.1753

25. Stranahan AM, Hao S, Dey A, Yu X, Baban B. Blood-brain barrier breakdown promotes macrophage infiltration and cognitive impairment in leptin receptor-deficient mice. J Cereb Blood Flow Metab (2016) 36(12):2108-21. doi $: 10.1177 / 0271678 X 16642233$

26. Zhang S, Dong H, Zhang X, Li N, Sun J, Qian Y. Cerebral mast cells contribute to postoperative cognitive dysfunction by promoting blood brain barrier disruption. Behav Brain Res (2016) 298(Pt B):158-66. doi:10.1016/j. bbr.2015.11.003

27. Wu X, Lu Y, Dong Y, Zhang G, Zhang Y, Xu Z, et al. The inhalation anesthetic isoflurane increases levels of proinflammatory TNF-alpha, IL-6, and IL-1beta. Neurobiol Aging (2012) 33(7):1364-78. doi:10.1016/j. neurobiolaging.2010.11.002

28. Shen X, Dong Y, Xu Z, Wang H, Miao C, Soriano SG, et al. Selective anesthesia-induced neuroinflammation in developing mouse brain and cognitive impairment. Anesthesiology (2013) 118(3):502-15. doi:10.1097/ ALN.0b013e3182834d77

29. Tao G, Zhang J, Zhang L, Dong Y, Yu B, Crosby G, et al. Sevoflurane induces tau phosphorylation and glycogen synthase kinase 3beta activation in young mice. Anesthesiology (2014) 121(3):510-27. doi:10.1097/ALN. 0000000000000278

30. Neuhaus W, Gaiser F, Mahringer A, Franz J, Riethmuller C, Forster C. The pivotal role of astrocytes in an in vitro stroke model of the blood-brain barrier. Front Cell Neurosci (2014) 8:352. doi:10.3389/fncel.2014.00352

31. Wylezinski LS, Hawiger J. Interleukin 2 activates brain microvascular endothelial cells resulting in destabilization of adherens junctions. J Biol Chem (2016) 291(44):22913-23. doi:10.1074/jbc.M116.729038

32. Zhang C, Zhang Y, Shen Y, Zhao G, Xie Z, Dong Y. Anesthesia/surgery induces cognitive impairment in female Alzheimer's disease transgenic mice. J Alzheimers Dis (2017) 57(2):505-18. doi:10.3233/JAD-161268

33. Ren Q, Peng M, Dong Y, Zhang Y, Chen M, Yin N, et al. Surgery plus anesthesia induces loss of attention in mice. Front Cell Neurosci (2015) 9:346. doi:10.3389/fncel.2015.00346

34. Xie Z, Culley DJ, Dong Y, Zhang G, Zhang B, Moir RD, et al. The common inhalation anesthetic isoflurane induces caspase activation and increases amyloid beta-protein level in vivo. Ann Neurol (2008) 64(6):618-27. doi:10.1002/ ana. 21548

35. Terrando N, Monaco C, Ma D, Foxwell BM, Feldmann M, Maze M. Tumor necrosis factor-alpha triggers a cytokine cascade yielding postoperative cognitive decline. Proc Natl Acad Sci U S A (2010) 107(47):20518-22. doi:10.1073/ pnas. 1014557107

36. Armulik A, Genove G, Mae M, Nisancioglu MH, Wallgard E, Niaudet C, et al. Pericytes regulate the blood-brain barrier. Nature (2010) 468(7323):557-61. doi:10.1038/nature09522

37. Barnes CA. Memory deficits associated with senescence: a neurophysiological and behavioral study in the rat. J Comp Physiol Psychol (1979) 93(1):74-104. doi:10.1037/h0077579

38. Nunes MA, Schowe NM, Monteiro-Silva KC, Baraldi-Tornisielo T, Souza SI, Balthazar J, et al. Chronic microdose lithium treatment prevented memory loss and neurohistopathological changes in a transgenic mouse model of Alzheimer's disease. PLoS One (2015) 10(11):e0142267. doi:10.1371/journal. pone. 0142267

39. Lin D, Cao L, Wang Z, Li J, Washington JM, Zuo Z. Lidocaine attenuates cognitive impairment after isoflurane anesthesia in old rats. Behav Brain Res (2012) 228(2):319-27. doi:10.1016/j.bbr.2011.12.010 
40. Zhang J, Tan H, Jiang W, Zuo Z. Amantadine alleviates postoperative cognitive dysfunction possibly by increasing glial cell line-derived neurotrophic factor in rats. Anesthesiology (2014) 121(4):773-85. doi:10.1097/ ALN.0000000000000352

41. Yoder RM, Kirby SL. Otoconia-deficient mice show selective spatial deficits. Hippocampus (2014) 24(10):1169-77. doi:10.1002/hipo.22300

42. Rosenfeld CS, Ferguson SA. Barnes maze testing strategies with small and large rodent models. J Vis Exp (2014) 84:e51194. doi:10.3791/51194

43. Flinn JM, Bozzelli PL, Adlard PA, Railey AM. Spatial memory deficits in a mouse model of late-onset Alzheimer's disease are caused by zinc supplementation and correlate with amyloid-beta levels. Front Aging Neurosci (2014) 6:174. doi:10.3389/fnagi.2014.00174

44. Jin R, Liu W, Menezes S, Yue F, Zheng M, Kovacevic Z, et al. The metastasis suppressor NDRG1 modulates the phosphorylation and nuclear translocation of beta-catenin through mechanisms involving FRAT1 and PAK4. J Cell Sci (2014) 127(Pt 14):3116-30. doi:10.1242/jcs.147835

45. Huang P, Senga T, Hamaguchi M. A novel role of phospho-beta-catenin in microtubule regrowth at centrosome. Oncogene (2007) 26(30):4357-71. doi:10.1038/sj.onc.1210217

46. Bell RD, Winkler EA, Singh I, Sagare AP, Deane R, Wu Z, et al. Apolipoprotein E controls cerebrovascular integrity via cyclophilin A. Nature (2012) 485(7399):512-6. doi:10.1038/nature11087

47. Bell RD, Zlokovic BV. Neurovascular mechanisms and blood-brain barrier disorder in Alzheimer's disease. Acta Neuropathol (2009) 118(1):103-13. doi:10.1007/s00401-009-0522-3

48. Zhong Z, Deane R, Ali Z, Parisi M, Shapovalov Y, O’Banion MK, et al. ALScausing SOD1 mutants generate vascular changes prior to motor neuron degeneration. Nat Neurosci (2008) 11(4):420-2. doi:10.1038/nn2073

49. Marcantonio ER. Postoperative delirium: a 76-year-old woman with delirium following surgery. JAMA (2012) 308(1):73-81. doi:10.1001/jama. 2012.6857

50. Braida D, Sacerdote P, Panerai AE, Bianchi M, Aloisi AM, Iosue S, et al. Cognitive function in young and adult IL (interleukin)-6 deficient mice. Behav Brain Res (2004) 153(2):423-9. doi:10.1016/j.bbr.2003.12.018

51. Cao XZ, Ma H, Wang JK, Liu F, Wu BY, Tian AY, et al. Postoperative cognitive deficits and neuroinflammation in the hippocampus triggered by surgical trauma are exacerbated in aged rats. Prog Neuropsychopharmacol Biol Psychiatry (2010) 34(8):1426-32. doi:10.1016/j.pnpbp.2010.07.027

52. Huang Y, Henry CJ, Dantzer R, Johnson RW, Godbout JP. Exaggerated sickness behavior and brain proinflammatory cytokine expression in aged mice in response to intracerebroventricular lipopolysaccharide. Neurobiol Aging (2008) 29(11):1744-53. doi:10.1016/j.neurobiolaging.2007.04.012

53. Patanella AK, Zinno M, Quaranta D, Nociti V, Frisullo G, Gainotti G, et al. Correlations between peripheral blood mononuclear cell production of BDNF, TNF-alpha, IL-6, IL-10 and cognitive performances in multiple sclerosis patients. J Neurosci Res (2010) 88(5):1106-12. doi:10.1002/jnr.22276

54. Schuitemaker A, Dik MG, Veerhuis R, Scheltens P, Schoonenboom NS, Hack CE, et al. Inflammatory markers in $\mathrm{AD}$ and $\mathrm{MCI}$ patients with different biomarker profiles. Neurobiol Aging (2009) 30(11):1885-9. doi:10.1016/j. neurobiolaging.2008.01.014

55. Katsumata Y, Harigai M, Kawaguchi Y, Fukasawa C, Soejima M, Takagi K, et al. Diagnostic reliability of cerebral spinal fluid tests for acute confusional state (delirium) in patients with systemic lupus erythematosus: interleukin 6
(IL-6), IL-8, interferon-alpha, IgG index, and Q-albumin. J Rheumatol (2007) 34(10):2010-7.

56. Hirano T, Yasukawa K, Harada H, Taga T, Watanabe Y, Matsuda T, et al. Complementary DNA for a novel human interleukin (BSF-2) that induces B lymphocytes to produce immunoglobulin. Nature (1986) 324(6092):73-6. doi:10.1038/324073a0

57. Biffl WL, Moore EE, Moore FA, Peterson VM. Interleukin-6 in the injured patient. Marker of injury or mediator of inflammation? Ann Surg (1996) 224(5):647-64. doi:10.1097/00000658-199611000-00009

58. Jones SC, Trejdosiewicz LK, Banks RE, Howdle PD, Axon AT, Dixon MF, et al. Expression of interleukin-6 by intestinal enterocytes. J Clin Pathol (1993) 46(12):1097-100. doi:10.1136/jcp.46.12.1097

59. Tovey MG, Content J, Gresser I, Gugenheim J, Blanchard B, Guymarho J, et al. Genes for IFN-beta-2 (IL-6), tumor necrosis factor, and IL-1 are expressed at high levels in the organs of normal individuals. J Immunol (1988) 141(9):3106-10.

60. Garre JM, Silva HM, Lafaille JJ, Yang G. CX3CR1+ monocytes modulate learning and learning-dependent dendritic spine remodeling via TNF-alpha. Nat Med (2017) 23(6):714-22. doi:10.1038/nm.4340

61. Dittmar MS, Petermichl W, Lindner R, Sinner B, Graf BM, Schlachetzki F, et al. In vitro induction of endothelial apoptosis of the post-hypoxic bloodbrain barrier by isoflurane but not by sevoflurane and midazolam. PLoS One (2015) 10(6):e0130408. doi:10.1371/journal.pone.0130408

62. Acharya NK, Goldwaser EL, Forsberg MM, Godsey GA, Johnson CA, Sarkar A, et al. Sevoflurane and isoflurane induce structural changes in brain vascular endothelial cells and increase blood-brain barrier permeability: possible link to postoperative delirium and cognitive decline. Brain Res (2015) 1620:29-41. doi:10.1016/j.brainres.2015.04.054

63. Cao Y, Ni C, Li Z, Li L, Liu Y, Wang C, et al. Isoflurane anesthesia results in reversible ultrastructure and occludin tight junction protein expression changes in hippocampal blood-brain barrier in aged rats. Neurosci Lett (2015) 587:51-6. doi:10.1016/j.neulet.2014.12.018

64. He HJ, Wang Y, Le Y, Duan KM, Yan XB, Liao Q, et al. Surgery upregulates high mobility group box-1 and disrupts the blood-brain barrier causing cognitive dysfunction in aged rats. CNS Neurosci Ther (2012) 18(12):994-1002. doi: $10.1111 / \mathrm{cns} .12018$

65. De Ita-Perez DL, Diaz-Munoz M. Synchronization by daytime restricted food access modulates the presence and subcellular distribution of beta-catenin and its phosphorylated forms in the rat liver. Front Endocrinol (2017) 8:14. doi:10.3389/fendo.2017.00014

66. Bienz M. beta-Catenin: a pivot between cell adhesion and Wnt signalling. Curr Biol (2005) 15(2):R64-7. doi:10.1016/j.cub.2004.12.058

Conflict of Interest Statement: The authors declare that the research was conducted in the absence of any commercial or financial relationships that could be construed as a potential conflict of interest.

Copyright (c) 2017 Yang, Gu, Mandeville, Dong, Esposito, Zhang, Yang, Shen, Fu, Lo and Xie. This is an open-access article distributed under the terms of the Creative Commons Attribution License (CC BY). The use, distribution or reproduction in other forums is permitted, provided the original author(s) or licensor are credited and that the original publication in this journal is cited, in accordance with accepted academic practice. No use, distribution or reproduction is permitted which does not comply with these terms. 